\title{
HIGH TEMPERATURE TRANSPARENT FURNACE DEVELOPMENT
}

\author{
Stephen C. Bates \\ Thoughtventions Unlimited \\ P.O. Box 1310 \\ Glastonbury, CT 06033
}

\section{SUMMARY}

This report describes the use of novel techniques for heat containment that could be used to build a high temperature transparent furnace. The primary objective of the work was to experimentally demonstrate transparent furnace operation at $1200^{\circ} \mathrm{C}$. Secondary objectives were to understand furnace operation and furnace component specification to enable the design and construction of a low power prototype furnace for delivery to NASA in a follow-up project.

The basic approach of the research was to couple high temperature component design with simple concept demonstration experiments that modify a commercially available transparent furnace rated at lower temperature. A detailed energy balance of the operating transparent furnace was performed, calculating heat losses through the furnace components as a result of conduction, radiation, and convection. The transparent furnace shells and furnace components were redesigned to permit furnace operation at at least $1200^{\circ} \mathrm{C}$. Techniques were developed that are expected to lead to significantly improved heat containment compared with current transparent furnaces. The design of a thermal profile in a multizone high temperature transparent furnace design was also addressed. Experiments were performed to verify the energy balance analysis, to demonstrate some of the major furnace improvement techniques developed, and to demonstrate the overall feasibility of a high temperature transparent furnace. The important objective of the research was achieved: to demonstrate the feasibility of operating a transparent furnace at $1200^{\circ} \mathrm{C}$.

\section{INTRODUCTION}

Although it is believed that there are many reasons for being able to achieve superior high temperature processing of materials in microgravity, major commercial applications are still being developed. A major cause for this is that the removal of gravity as a driving force has led to the discovery of a series of more subtle phenomena such as surface tension that have limited successful materials processing in space. These phenomena have so far been inferred and investigated based on the final state of materials that have been processed in space. Most high temperature materials processing conditions are set by general principles, experience and iteration. Non-intrusive, in-situ diagnostics are needed for research and optimum process control in the presence of these effects. Experiments using optical diagnostics must begin with measurement of unknown optical properties such as emissivity and index of refraction at high temperature. Full optical access to furnace applications is needed for diagnosis and feedback control of the subtleties of high temperature processes under microgravity conditions.

Small furnace windows are currently used to provide access for assessing crystal quality, but only small portions of the object can be viewed and these windows themselves cause heat disturbances that affect the growth process. Also, many semi-transparent materials of interest have a large index of refraction that makes single direction viewing of an entire piece very difficult. Transparent furnaces are in use, but at relatively low temperatures because these furnace systems cannot survive the temperatures and heat loads required at high temperature. Specifically, current reflective coatings designed to contain thermal radiation have severe 
limitations. There is a great need to develop advanced transparent furnace technology for material processing research at high temperatures.

The innovation of this project is the use of advanced techniques for heat containment and high temperanure optical materials to build a transparent furnace rated at $1200^{\circ} \mathrm{C}$ or higher. Full optical access to furnace applications is needed to diagnose the subtleties of high temperature processes under microgravity conditions, as well as for future applications in manual and automatic process control in space and on earth. Advanced high temperature radiation containment methods, convection reduction, high temperature transparent materials, and improved transparent heater component design are combined to achieve a significantly higher temperature rating compared with current technology. Phase I has demonstrated transparent furnace operation at $1200^{\circ} \mathrm{C}$ by coupling energy balance analysis and heat shield design with simple modifications to a currently available transparent furnace. Furnace performance has been predicted and additional design strategies for major improvements in the follow-on project have been developed. A high temperature transparent furnace will create many new opportunities for high temperature material processing research and process control applications. These furnaces may be the necessary means for developing commercial materials processing in space.

\section{BACKGROUND}

\section{Transparent Furnaces}

Transparent furnaces have been used in ground-based research for many years, in a concept first invented and patented at MIT [1]. They have been used in space in shuttle experiments where visibility of the process is crucial for performing rapid experiments [2-4]. Transparent furnaces are used for research in areas that include crystal growth, metal bonding, combustion, solar energy, biomass energy conversion, and others. The ability to observe processes within the furnace can provide information unobtainable from post-cooldown sample characterization. In the area of crystal growth the in-situ, non-intrusive observational capability of a transparent furnace leads to the ability to change the growth ampoule temperature and/or temperature profile. As a specific example, control of the visible onset of nucleation and growth of crystals is far superior to preprogrammed techniques that are typically used with standard furnaces.

A standard earth-based transparent furnace uses a thin gold mirror coated onto the wall of a quartz tube to surround the hot zone of a furnace and contain infrared (IR) radiation. A typical furnace being used for crystal growth is shown schematically in Fig. 1. The mirror coating has the characteristic that it is reflective for longer wavelengths of radiation in the IR and transparent at shorter wavelengths in the visible. Depending on the details of the coating, approximately $95 \%$ of the incident infrared energy is reflected while roughly $80 \%$ of the visible radiation is transmitted. Typically over $90 \%$ of the total energy incident from a $850^{\circ} \mathrm{C}$ blackbody is reflected. The thin film gold coating is an effective radiant heat insulator while simultaneously allowing a clear view of processes occurring within. Furnace heating energy is provided by one or more helically wound resistance heating elements that have a coil spacing large enough to permit good visibility through the coils. A quartz shield tube is located between the heater and mirror to prevent the outgassing heater material from coating the mirror, reducing its reflectivity. A quartz 'muffle' tube is mounted between the heater and the growth ampoule, acting as an impurity barrier for the growth ampoule and reducing hot spots. The crystal growth ampoule is located along the axis of the furnace inside the muffle tube.

The primary constraints on future transparent furnace development are in the areas of transparent shell materials and radiation containment coatings. Current technology uses fused silica tubes, whereas much higher temperature versions will use materials such as sapphire. Subsidiary issues are the binding of the reflective coating to the substrate and the ability of these coatings to survive high temperatures. To date, multizone transparent furnaces have been limited to temperature ratings of approximately $1000^{\circ} \mathrm{C}$. 

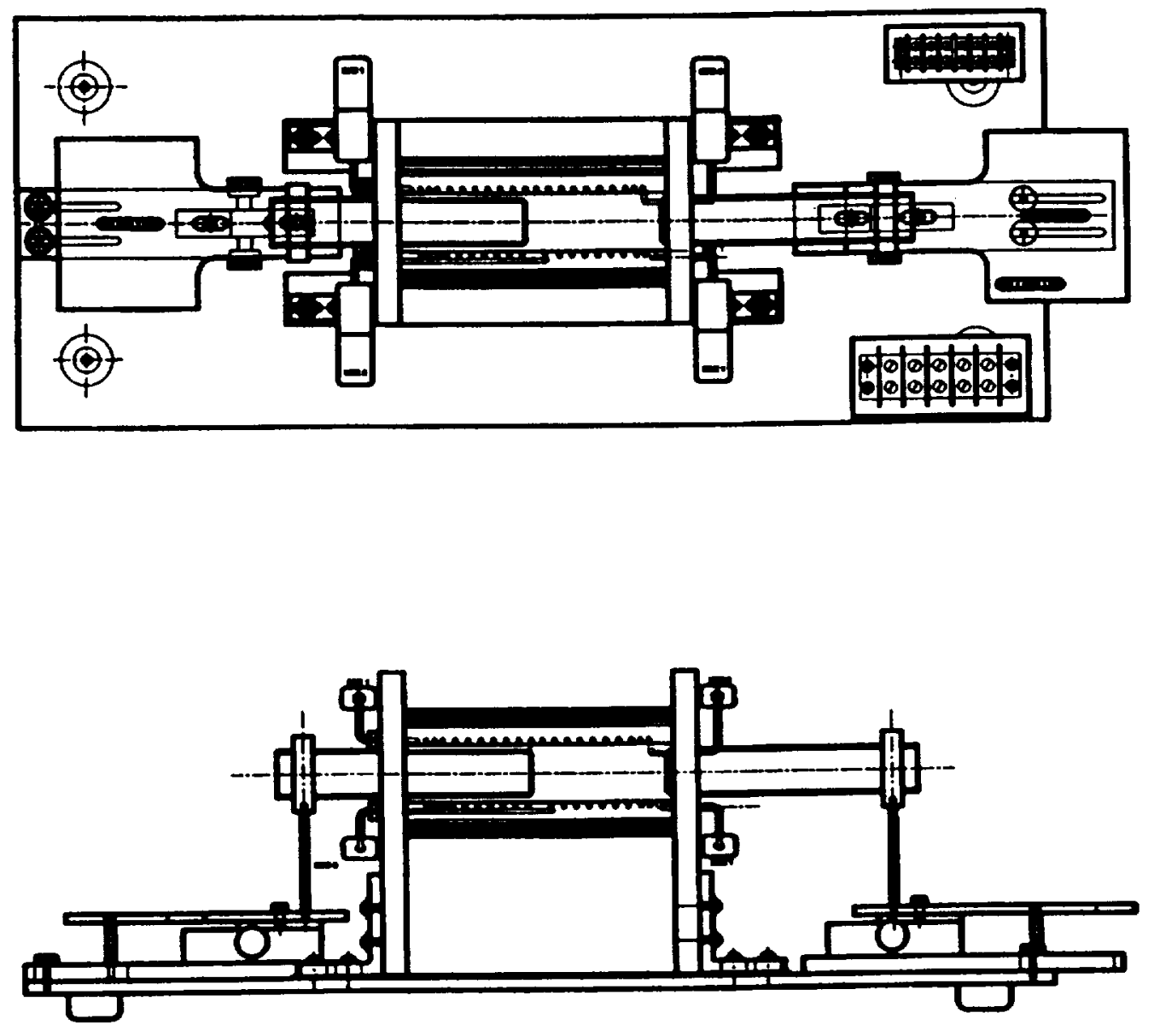

Figure 1. Transparent furnace schematic. 


\section{High Temperature Heat Transfer}

At high temperatures radiant heat transfer is the dominant mechanism for heat loss, assuming no flowing or boiling liquids, and no large-area, high thermal conductivity solid contact between the hot zone and the environment. Radiation heat loss is defined by the Planck function as it describes blackbody radiation - a body that absorbs all incoming radiation.

$$
\left.W(\lambda, T)=c_{1} /\left[\lambda^{5}\right)\left(e^{c / \lambda T}-1\right)\right]
$$

Where $W(\lambda, T)$ is defined as the power radiated per unit wavelength interval at wavelength $\lambda$ by unit area of a blackbody at temperature $T$ in measured in degrees $K$. $c_{1}$ and $c$ are constants. The total radiated power by a blackbody at temperature, $T$, is given by the familiar Stefan-Boltzmann function:

$$
W_{\text {toata }}(T)=5.679 \times 10^{-12} T^{4} \quad W / \mathrm{cm}^{2}
$$

The $T^{4}$ dependence of the radiated power accounts for the dominance of radiation at high temperatures. For real materials the total radiated power differs from that of a blackbody by the total emittance, $\varepsilon_{l}$, such that

$$
W_{\text {reas }}(T)=\varepsilon_{q}(T) W_{\text {blackbody }}(T)
$$

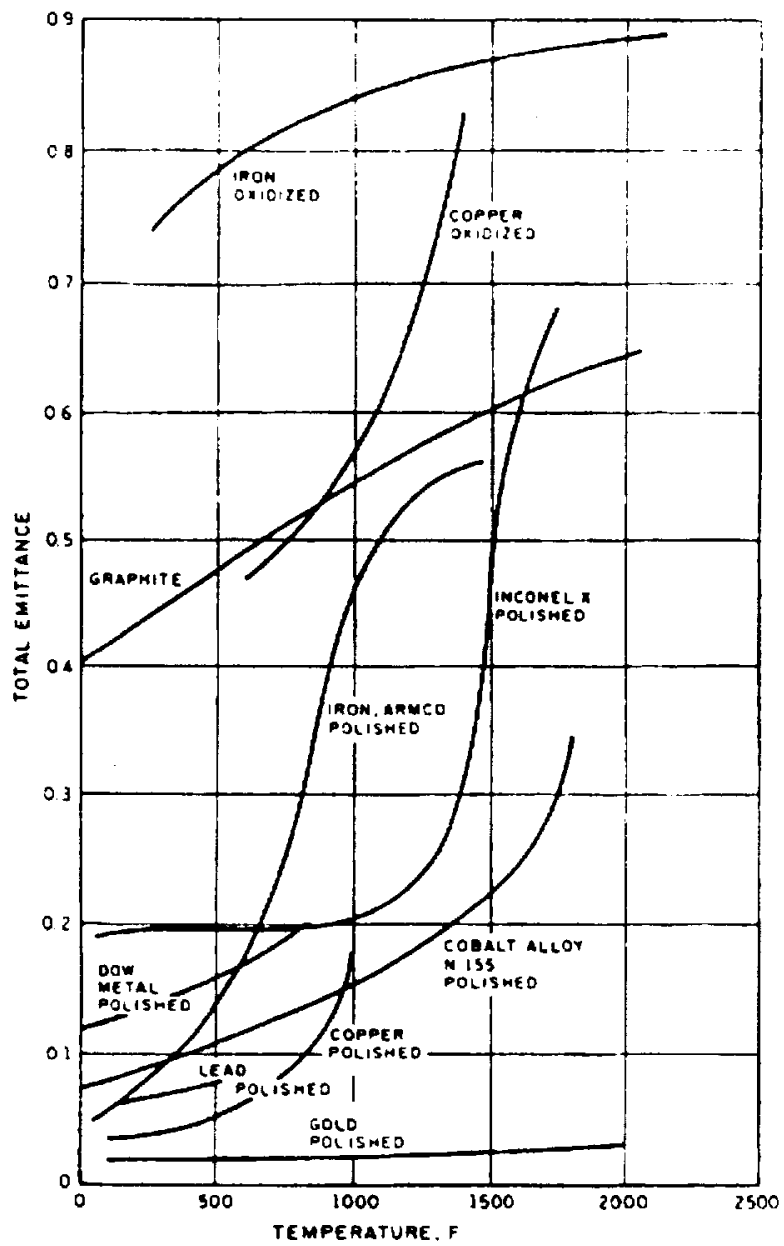

Figure 2. Total emittances of common materials versus temperature. 
Total emittances are integrals over wavelength of detailed emissivities that are also wavelength dependent. Total emittances can be quiet low, but also can depend strongly on temperature, usually increasing with temperature. Examples of commonly used materials are shown in Fig. 2.

Heat transfer as a result of convection and conduction can be estimated by using a thermal resistance concept:

$$
R_{\text {thermal }}=\Delta T / q
$$

where $\Delta \mathrm{T}$ is the temperature difference across the resistance path and $\mathrm{q}$ is the heat flux entering the resistance. A contact coefficient of heat transfer, $h_{s}$, is $R / A$, where $A$ is the contact area. For a wall, $h=k / t$, where $k$ is the thermal conductivity, and $t$ is the wall thickness. Orders of magnitude for $h$ in $W / m^{2}-K$ are: 1) Gases in natural convection: 5-29, 2) Flowing gases: 11-290, and flowing liquids (non-metallic): 170-5700.

Convection can be eliminated by using vacuum enclosures. Conduction can be reduced by limiting contact area and using materials of low thermal conductivity (quartz). Thermal radiation can be reduced by using materials of low thermal emissivity.

\section{Transparent Furnace Applications}

There are many possible uses for transparent furnaces, including sintering, metal joining, and annealing, but current applications center on crystal growth. For this application, some of the capabilities introduced by a transparent furnace are 1) Nucleation can be observed; if multiple nucleation sites occur solidification can be restarted, 2) The melt/solid interface can be viewed as a result of differences in density and emissivity between the liquid and solid, 3) Surface tension effects can be studied as a result of these liquid-solid differences. (This capability is important for microgravity research), 4) Convection can be studied through index of refraction changes with temperature, 5) Internal temperatures can be monitored by tomographic means, and 6) A variety of crystal defects are visible, depending on the optical properties of the crystal. Together, these advantages provide a powerful incentive to use transparent furnaces. The incentives will be further enhanced when standard optical diagnostics are produced to monitor processes in these furnaces. Typical of what can be seen in a transparent furnace are the images of Fig. 3, showing the glowing crystal, and defects at two magnifications. A case study in the actual benefits of transparent furnace use is given by Schunemann and Pollak [5]. In this work simple visual access to the process allowed drastic reductions (a factor of 10) in the time needed to develop a process for $\mathrm{ZnGePh}$. An increasing amount of work is being done in the area of intelligent processing of materials [6,7]; optical access and optical diagnostics are playing a key role in this effort.

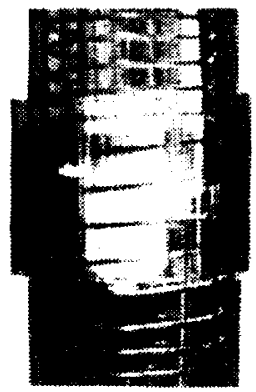

Test Chamber in Furnace

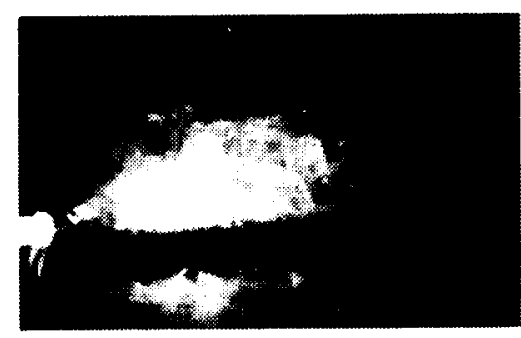

Thru microscope (2X)

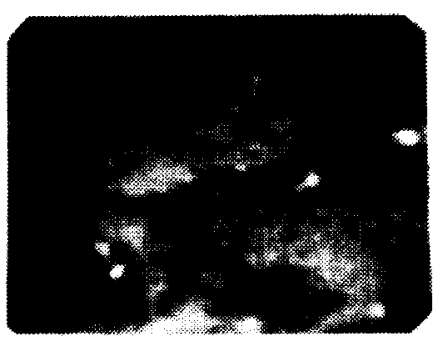

Enhanced image on monitor $(47 X)$

Figure 3. Transparent furnace crystal growth images. 
Crystal Growth - There are a number of techniques that can be used to grow crystals, including vapor phase growth [8], solution growth [9] and melt growth [10], are used to obtain crystals. Figure 4 shows the construction of the electric furnace and temperature profile for typical Bridgman crystal growth with vapor control of composition [11]. In a transparent furnace the quartz ampoule is the container for the material. The typical temperature profile has an isothermal in the upper zone, a $20^{\circ} \mathrm{C}$ temperature elevation in a middle region of 2.5 $\mathrm{cm}$ long at the melt-solid interface, and a bottom zone cooling gradient of $25^{\circ} \mathrm{C} / \mathrm{cm}$. Crystals can be grown from a seed or seedless. The ampoule is translated through the temperature field and the crystal grows at a rate of $2-4$ $\mathrm{mm} / \mathrm{hr}$.

Research has indicated that the achievement of improved crystalline and chemical perfection in single crystals grown using the vertical Bridgman technique is to a significant extent dependent on the ability to control the morphology of the growth interface [12], which will be visible using a transparent furnace. Recent analyses furthermore indicate that thermal conditions inherent to the Bridgman method, referred to as the "interface effect ${ }^{\prime}$, in principle reduce the effectiveness of conventional means for controlling the interface shape.

The interface effect is due to a difference in the thermal conductivities of the melt and the crystal and/or the release of latent heat at the growth interface in the presence of a charge confining crucible. Such conditions lead to a change in the axial temperature gradient of the charge at the growth interface whereas the axial temperature gradient of the crucible is continuous [12]. A temperature difference (and, thus, heat exchange) between the charge and crucible results, causing the interface shape to be nonplanar. For semiconductors, whose thermal conductivity of the melt is greater than that of the solid, the charge is cooled by the crucible and therefore the interface shape is such that the crystal is concave. Experimental evidence for this behavior is provided, for example, by Lehoczky and Szofran [13] who first described the interface effect in order to explain observed segregation data in Bridgman-grown $\mathrm{Hg}_{1-x} \mathrm{Cd} \times \mathrm{Te}$. In the case of semi-transparent crystals this interface can be monitored using a variety of optical diagnostics, depending on the properties that change from the liquid to solid state.

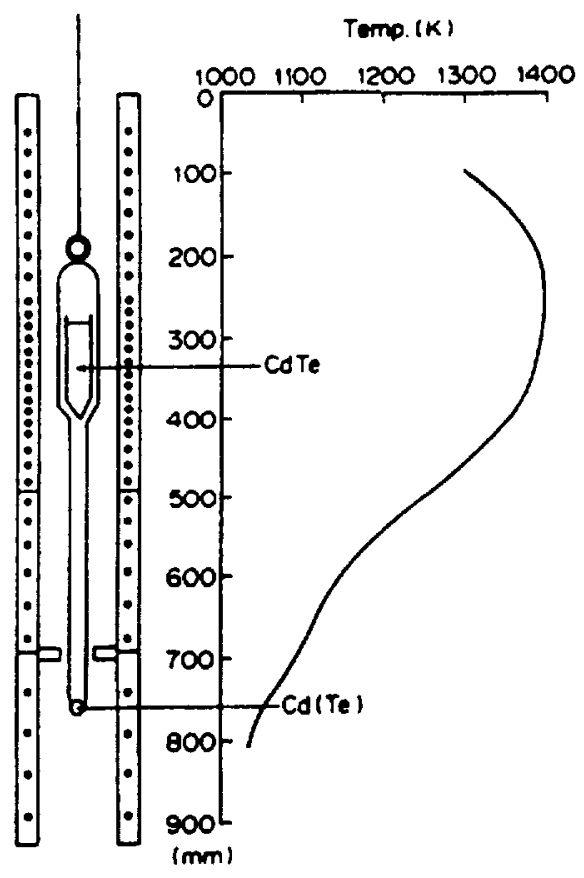

Figure 4. Schematic construction of an electric furnace and a typical temperature profile for Bridgman crystal growth [11]. 


\section{PROGRAM APPROACH}

The goal of this program has been to provide an experimental demonstration of transparent furnace operation at $1200^{\circ} \mathrm{C}$ thereby proving techniques that can be used to construct a prototype furnace in a follow-on project that will operate reliably at this temperature.

The project work has shown how complex the heat transfer is inside the standard transparent furnace. It has also been shown how difficult it is to obtain a high temperature mirror coating. Operation at $1200^{\circ} \mathrm{C}$ was achieved by using forced-air cooling to keep the mirror temperature low at the price of increased furnace power. Solutions to all of these problems have been found for the design and construction of a much improved prototype transparent furnace.

\section{ENERGY BALANCE ANALYSIS}

\section{Introduction}

The overall goal of this task has been to analyze the energy flows in the transparent furnace and to identify the major heat losses of the system together with their dependence on furnace parameters. By minimizing system heat losses one can 1) minimize the temperature of all of the components in the furnace, 2) minimize the electrical power required to obtain a specific sample temperature,

Table 1. Transparent furnace project parameters

Furnace axis

Furnace power

Muffle tube inside diameter/outside diameter(ID/OD)

Heater element diameter; coil/wire

Heater element support (fused to muffle tube)

Shield tube ID/OD

Buffer tubes ID/OD

Mirror tube ID/OD

Overall length of quartz elements

Heated length

Heater element

Furnace end insulation
Horizontal

AC feedback controlled

$37 / 40 \mathrm{~mm}$

$65 / 1.52 \mathrm{~mm}$

Three $1 \mathrm{~cm}$ diam. slotted rods

$70 / 75 \mathrm{~mm}$

Varies

Varies

$215 \mathrm{~mm}$

$180 \mathrm{~mm}$

Kanthal AF

Alumina felt

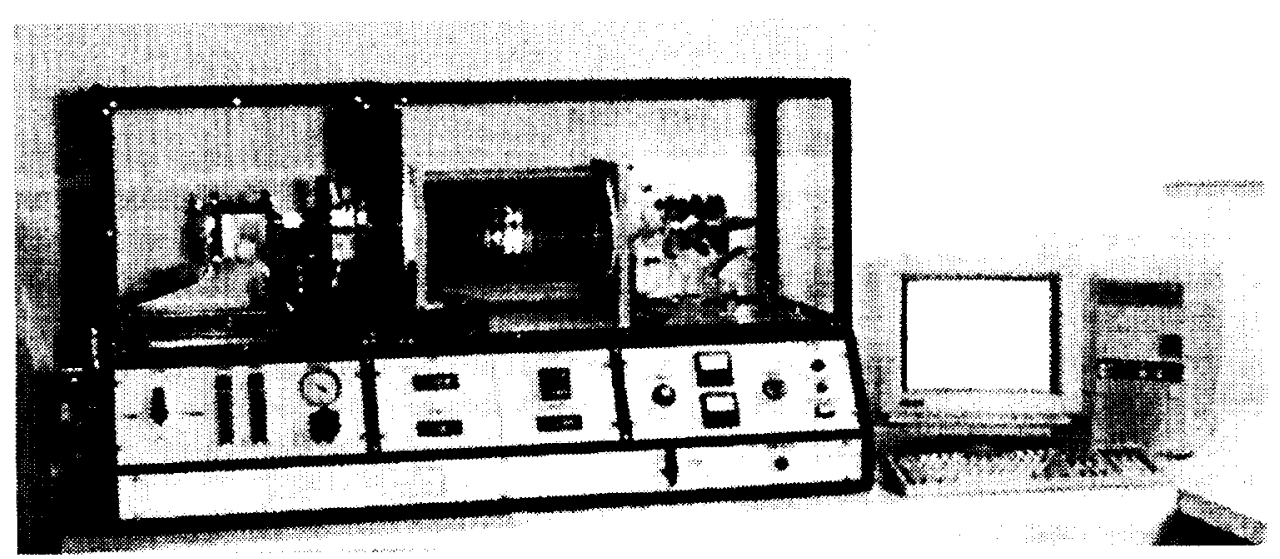

Figure 5. High temperature commercial transparent furnace sold by $\mathrm{C} / \mathrm{VI}$. 
and 3) minimize the overall heat release of the furnace. In the project, the energy balance effort centers on the characteristics of the furnace that presently limit operating temperature. In the follow-on project the primary research effort will be directed toward furnace redesign to optimize operation by minimizing heat losses in general and electrical power requirements in particular.

\section{Overall Energy Balance}

Since the transparent furnace operates as a steady state device the power dissipated as an electrical load in its heating element must equal the heat power lost from the furnace through convection, radiation, and conduction at the external envelope of the furnace. The heat power emerges from the furnace either as 1) radiation that is transmitted directly from the heating element to the external environment through all of the inner quartz shells and the mirror tube, or 2) heat that has been relayed by convection, conduction, and radiation to the external shell where it is primarily carried away by natural convection, assuming an uncooled system. Conduction losses are all end losses through the gas tubing connections, the electrical connections, and the supports for the quartz shells. Conduction losses also finally become primarily convective losses in this case, rather than being absorbed to heat solid objects because of minimal large-area thermal contact.

Heat transfer theory is well known in general but has a number of critical factors that are difficult to calculate in detail. These factors include emissivity, contact resistance, complex geometric effects, and flow patterns for convective heat loss. High temperature heat transfer is dominated by radiant heat transfer in most cases, increasing in proportion to $T^{4}$ (in degrees $\mathrm{K}$ ), because careful thermal isolation must have been done to achieve such temperatures for practical heating powers. For transparent furnaces, most of the heat absorbed by a workpiece is transferred by radiation, and this radiation must be contained in the furnace the by IR mirrors at the outside of the furnace. In standard furnaces the walls are opaque, thermally isolated, and in radiant equilibrium at high temperatures with the entire interior of the furnace.

Previous Experimental Data - A large amount of data on transparent furnaces is available to this program through the extensive work done in the past by Insight Scientific in their transparent furnace business. The most important data for the purposes of determining the proportion of beat lost through convection, conduction, and radiation has been obtained from a furnace operated at $900^{\circ} \mathrm{C}$ both in air and in vacuum. This furnace had the standard geometry, with a quartz muffle, shield, and mirror tube, and a standard gold coating on the outside of the mirror tube. To achieve a $900^{\circ} \mathrm{C}$ sample temperature the furnace required $1800 \mathrm{~W}$ of power operating in air, whereas in vacuum it required 600 to $650 \mathrm{~W}$. Further measurements showed that in vacuum, $1 / 3$ of the heat was lost radially (radiation), and $1 / 3$ was lost out each end. The data indicates that for a $900^{\circ} \mathrm{C}$ sample temperature (the filament was hotter) approximately $2 / 3$ of the heat was lost as a result of convection and $1 / 3$ was lost through radiation and conduction. This data also provides a basis for comparison with analytical quantitative prediction of the heat losses. Other data this is available is the typical electrical power dissipated per unit of furnace surface area, and mirror surface temperatures that have resulted from previous attempts at high temperature operation.

\section{Convection}

The transparent furnace data that implies that $2 / 3$ of the heat transfer in the furnace occurs as a result of the presence of atmospheric pressure gas in the furnace initially indicates that convective heat transfer dominates the heat transfer inside the furnace up to approximately $1000^{\circ} \mathrm{C}$. This convective heat transfer must occur as a result of gravity driven buoyant laminar free flow. Between the cylindrical shells there are tangential flows around the shells that are driven by buoyancy forces resulting from density differences in the gas that are in turn caused by temperature differences. The inner shell is hotter, so the heated gas next to this shell rises from the bottom to the top, then cools and falls near the cooler outer shell. Nominally, two circulating flows occur as shown in Fig. 6, but the actual flows are more complex as a result of three-dimensional effects. The flows that travel along the inner and outer faces of the tubes greatly enhance the heat transfer between the hot inner tube and the cooler outer tube compared with conduction through the gas.

To estimate how the magnitude of convective heat transfer changes with furnace parameters, its analytical form was investigated. Natural convection can occur as a laminar or turbulent flow, where hotter objects cause larger buoyancy forces, higher flow rates, and turbulent flows. The flow regime is determined by both the 
Prandtl Number ( $\mathrm{Pr}=$ ratio of momentum to thermal diffusivities) and the Grashof Number ( $\mathrm{Gr}=$ ratio of buoyancy to viscous forces). The convective flows are laminar in the case considered here [14], where

$$
10^{4}<\operatorname{GrPr}<10^{9}
$$

Figure 6. Internal natural convection cooling flows between cylindrical shells in the transparent furnace.

Data for horizontal cylinders in air have been correlated [14] to give the result

$$
\mathrm{q} / \mathrm{A} \propto \Delta \mathrm{T}^{5 / 4} / \mathrm{D}^{1 / 4}
$$

Where $\mathrm{q} / \mathrm{A}$ is the heat flux per unit area, $\Delta \mathrm{T}$ is the temperature difference between the hot surface and the environment, and $\mathrm{D}$ is the tube diameter. The heat flux thus essentially scales as $\mathrm{T}$, with a minor dependence on the tube diameter.

It should be noted that there is an optimum spacing for minimal convective heat transfer between two concentric tubes with an air gap. A large separation allows higher flow velocities to be created and thus large amounts of convection losses, whereas a very small separation leads to relatively large conduction losses. The optimum is defined by a gap that is small enough that the inner and outer buoyant flows interfere with each other and large enough that air conduction is not important. This optimum gap should be on the order of a few $\mathrm{mm}$, as is typically used in the furnace construction in the project. This description of free convection heat transfer is strongly geometry dependent; the flows and heat transfer between a tube and a surrounding polygon, as used late in the experiments, is quite different.

\section{Radiation}

Objects that have a high emissivity and are much hotter than $500^{\circ} \mathrm{C}$ emit enough radiation to be visible to the naked eye in a dark room. However in terms of heat flow, radiation is insignificant relative to other factors at this temperature for objects that are not isolated in vacuum. For a transparent furnace the radiative heat flows depend on the temperature and radiating characteristics of the hot sources. The driving source of radiation is the heating element, which is a metal (kanthal) in the case of the $1200^{\circ} \mathrm{C}$ transparent furnace used in this program. Derivative sources, which can be major radiators, are the sample itself as well as the quartz tubes and support rods that surround the heater element. All radiative sources emit as blackbodies modified by the emissivity of their surfaces, which depend on the wavelength of the radiation and a variety of surface properties. Determining the detailed emissivities and absorbances of the mirror shell is important, since radiant heat transfer dominates the energy balance at the high temperatures involved in this program. Although radiation containment dominates the furnace design more and more at higher temperatures, small losses as a result of all causes become significant because the internal heat fluxes are so large and the tolerable external heat fluxes are fixed.

Overall radiation confinement by the mirror tube is diminished by 1) absorption of a significant fraction of the radiated energy (discussed below) by the quartz outer shell (the mirror tube), and 2) the eventual escape of much of the radiant energy initially contained by the mirror tube through the large end holes after a few reflections. At high temperatures the radiated power rapidly grows to become equal and then to dominate the overall heat transfer because of its $T^{A}$ dependence, so that at the higher temperatures that are being attempted in this program, radiation containment becomes crucially important for the overall containment of heat in the furnace and its electrical efficiency.

The wide spacing and relatively small diameter of the heater coils makes the total radiating area of the coil relatively small, so that the total radiated power from the furnace will be significantly increased by adding a large sample in the furnace even though the sample is at a somewhat lower temperature than the coils. The quartz tubes are in large part transparent, but have been shown to play a major role in the radiated heat flux because of 
their large area. The quartz used in transparent furnaces has a low $\mathrm{OH}$ concentration, and is transparent ( $\alpha=$ absorptivity $=0$ ) for all wavelengths less than approximately $4 \mu \mathrm{m}$. whereas more typical quartz is opaque at wavelengths larger than $3 \mu \mathrm{m}$. The absorptivity of a material surface equals its emissivity, so the quartz in the furnace absorbs and radiates at wavelengths longer than $4 \mu \mathrm{m}$. Another factor to be considered is that the absorption edge moves to lower wavelength as the temperature of the quartz increases. The outer shell is relatively cool, whereas the inner tubes are hot, so there will be a small disparity in emission and absorption in the shells that is too complex to be considered here.

The transmission versus wavelength of quartz is especially important in terms of radiant heat flux for the mirror tube. The mirror tube nominally reflects the IR radiation incident on it to contain the radiant heat in the furnace. In the present transparent furnace, however, absorption in the mirror coating and in the quartz itself (because the mirror coating is on the outside of the quartz tube) degrade the efficiency of the IR radiation reflection. The mirror coating is on the outside of the tube because the vapor deposition coating process is much less expensive and superior coatings are obtained in this coating geometry.

Quartz absorbs all radiation beyond 3 - $5 \mu \mathrm{m}$ wavelength, depending on the type of quartz used. The mirror tube in a transparent furnace uses special IR transmissive quartz (GE type 124). For thicknesses over 1 $\mathrm{mm}$, this quartz absorbs all radiation with wavelengths longer than $5 \mu \mathrm{m}$. Absorption begins at about $4 \mu \mathrm{m}$ and is $40 \%$ at $4.5 \mu \mathrm{m}$. Assuming a sharp absorption cutoff at $4.5 \mu \mathrm{m}$ (a good approximation) the radiative power absorbed in the quartz can be calculated by integrating the blackbody spectrum given above from $4.5 \mu \mathrm{m}$ to infinite wavelength. Table 2 below gives the fraction of radiant power absorbed, the absolute power absorbed, and the total power emitted for quartz and sapphire (assumed to cutoff at $6 \mu \mathrm{m}$ ). Sapphire is included as a possible replacement for quartz to reduce absorption. Power absorbed is presented as power per unit area of the radiator (not the absorber). The absorption in the quartz is a significant part of the total radiated power at the temperatures relevant to this program. The use of sapphire reduces the absorption in the mirror tube by about a factor of two, whereas $\mathrm{ZnSe}$ (transparent to $20 \mu \mathrm{m}$ ) makes the absorption insignificant. The mirror coating also absorbs about $10 \%$ of the radiation as a result of the high absorptivity of the very the thin layer of binder that is necessary for the adhesion of the reflective gold film to the quartz

It is important to note that although the fraction of power deposited in the quartz decreases with temperature, the absolute magnitude of the power deposited increases steadily; not as fast as the total power Table 2. Absorption of blackbody radiation in quartz and sapphire at transparent furnace temperatures. Power absorbed is presented as power per unit area of the radiator (not the absorber).

$\begin{array}{ccrrrr}\begin{array}{c}\text { Temperature } \\ \text { (C) }\end{array} & \begin{array}{c}\text { Quartz } \\ \text { Abs. }\end{array} & \begin{array}{r}\text { Power Abs. } \\ \left(\mathrm{W} / \mathrm{cm}^{2}\right)\end{array} & \begin{array}{r}\text { Sapphire } \\ \text { \% Abs. }\end{array} & \begin{array}{r}\text { Power Abs. } \\ \left(\mathrm{W} / \mathrm{cm}^{2}\right)\end{array} & \begin{array}{r}\text { Total Power } \\ \left(\mathrm{W} / \mathrm{cm}^{2}\right)\end{array} \\ 900 & 32 & 3.5 & 18 & 1.9 & 10.7 \\ 1000 & 27.5 & 4.1 & 15 & 2.2 & 14.8 \\ 1100 & 24 & 4.8 & 13 & 2.5 & 20.2 \\ 1200 & 20.5 & 5.5 & 11 & 2.9 & 26.7\end{array}$

$\left(T^{4}\right)$, but with a dependence between $T^{2}$ and $T^{3}$. This power deposition will be a more significant problem as the temperature rating of the furnace increases.

A temperature increase from approximately $925^{\circ} \mathrm{C}$ to $1150^{\circ} \mathrm{C}$ implies an increase by a factor of 2 in radiated power as a result of the $\mathrm{T}^{4}$ power dependence. As the radiated power increases the radiation must be more efficiently contained to maintain the same level of deposited external power. The standard gold coatings used in previous transparent furnaces survive a temperature as high as $400-500^{\circ} \mathrm{C}$; beyond this temperature the coatings degrade. This temperature is easily exceeded by trying to operate at higher temperature.

Another aspect of radiation containment is end losses. Once the mirror tube has been optimized to maximize the reflection of IR radiation, multiple reflections followed by loss out the ends must be considered. To date there has been no attempt to contain end radiation, and it is estimated that over half of the radiation reflected at the mirror tube wall may be finally lost in this way in vacuum operation, rather than being reabsorbed by 
components in the furnace to reduce the electrical power required for heating. A typical furnace geometry has a mirror tube of $85 \mathrm{~mm}$ OD and $215 \mathrm{~mm}$ in length. With this aspect ratio there are major end losses. Longer mirror tubes have been built, which would reduce the problem, but eventually end losses will have to be reduced by reflectors at the ends of the tubes.

\section{Conduction}

Conductive heat losses in the transparent furnace are insignificant relative to convective and radiative heat transfer. This is a result of the low thermal conductivity of the quartz and the ceramic end mounts, and the small cross-sectional area of the electrical conductors and other gas flow attachments. That conductive losses are small is confirmed by 1) the small change increase in temperature of the furnace as the end fittings heat slowly, and 2) the low temperature of the end fittings during operation.

\section{Energy Balance Analysis}

In the first part of the project research the basic energy balance in the transparent furnace was thought to be similar to standard furnace with convective gas heat transfer between insulating walls. This belief was motivated by the vacuum versus atmospheric pressure furnace power data mentioned above. The reduction by almost $2 / 3$ of the power requirement for furnace operation at $900^{\circ} \mathrm{C}$ seemed to imply that convective heat transfer was causing most of the heat transfer in the furnace. It was known that there was radiant heat transfer to the absorbent binder in the mirror tube and radiant cooling of the outside of the mirror tube, but this was thought to only modify the convective cooling of the mirror tube, together determining the heat flux radially out of the furnace.

If convection dominates, a simple model of heat resistances (modified for mirror tube radiation absorption and emission) can be formed using heat flow resistances. Heat conduction within each quartz shell can be relatively easily calculated, assuming no corrosion or other types of interface layers have built up in the system. Heat transfer as a result of convection and conduction can be estimated by using a thermal resistance concept.

An algebraic computer model of the heat transfer in the transparent furnace was then created using MATHCAD ${ }^{\mathrm{TM}}$. The model is given in Appendix A. Temperatures are chosen for the coil and the quartz shells, and the heat transfer between components are then calculated using standard radiation heat transfer and relevant convective heat transfer correlations [14]. A correct solution is found when the heat transfer is the same through each interface of a cylindrical shell except for the radiant heat transfer at wavelengths less than $4 \mu \mathrm{m}$ that is deposited directly into the mirror tube. Iteration is rapid since the calculations are instantaneous once the temperatures are entered.

This model was first used to attempt to predict outside mirror tube temperatures, since previous furnace operation was limited by degradation of the mirrors at high temperatures. When only convective heat transfer in the gas and conductive heat transfer in the quartz were included, significantly lower temperatures (and thus heat transfer) were predicted for the quartz shells than were measured experimentally. Investigation showed the surprising fact that the radiant heat transfer between quartz shells at wavelengths longer than $4.5 \mu \mathrm{m}$ was not only a significant means of heat transfer, it actually dominates the heat transfer at higher temperatures. The model was then changed to add long wavelength radiant heat transfer from shell to shell and it was then found to match the experimental data much better. The model was found to be sensitive enough to the radiant heat transfer that a detailed approximation to the integrated blackbody power versus wavelength at an arbitrary temperature had to be added.

The proper description of the internal heat transfer in the specific case of a high temperature transparent furnace is thus that the convective heat transfer results in quartz shell temperatures which lead to more radiant heat transfer than is caused directly by the convection itself. The dynamics of radiant heat transfer are thus separate for wavelengths shorter than 4 microns and for longer wavelengths.

The model can first be used to analyze the vacuum/pressurized furnace operation discussed above. The furnace used for these tests was very similar to that used in the initial tests of the project; the standard transparent furnace configuration. The heating element wire was smaller $0.6 \mathrm{~mm}$ in diameter, and the coil dimensions were 
approximately as used in this program. Assuming a coil temperature of $970^{\circ} \mathrm{C}$ in vacuum and an emissivity of 0.7 (as with kanthal) the model predicts a radiated power of 650 watts, as was reported. In vacuum the heat transfer is all radiant from the heater coils. The model does not properly account for end losses, which are known to account for $2 / 3$ of the power in vacuum operation. Predicted heat transfer in the system is about 350 watts, and the predicted shell temperatures are $555^{\circ} \mathrm{C}$ and $312^{\circ} \mathrm{C}$ for the inside of the shield tube and the inside of the mirror tube respectively assuming the outside of the mirror tube is in air. Presumably end losses account for the additional power above the $216 \mathrm{w}$ (1/3 of radiant power) because of the large apertures at each end through which the direct and reflected coil radiation can be lost.

The model heat transfer is dominated by the radiation from quartz shell to quartz shell. This implies a very different radial temperature profile and heat losses in pressurized operation. As a result of convection the muffle and inner shield tube temperatures are approximately equal and equal to the core temperature. This has been the case in all suggested by experimental measurements. This is not true at all in vacuum operation, since the inner shield tube can cool itself by radiation to reach a much lower temperature than the muffle tube and the coil. This leads to the important conclusion that the end losses are significantly reduced for pressurized operation because the heat transfer in the furnace is dominated by the $>4 \mu \mathrm{m}$ wavelength radiation coming outward from the inner shield tube that is in equilibrium with components inside it. Whereas the core and muffle tubes have large openings at each end, the inner shield tube is closely confined on the outside by the mirror tube or buffer tubes.

For the above case of $900^{\circ} \mathrm{C}$ operation, the outside of the mirror tube is predicted to be at $520^{\circ} \mathrm{C}$ for natural convection cooling. For a coil temperature of $1020^{\circ} \mathrm{C}$, where the added $50^{\circ} \mathrm{C}$ is needed to supply the much higher power levels required, the power transmitted through the system is predicted to by approximately 870 watts, and the power radiated by the coil 780 watts. If end losses are approximately 400 watts (half the coil radiant power as in vacuum operation), the measured power consumption of 1800 watts is the result since $30 \%$ of the coil radiation is absorbed in the quartz. The model is thus in good agreement with this experimental data. In this case the radiant power from the inner shield to the mirror tube is about 3 times the convective heat flow.

The power flow in a typical transparent furnace is thus a subtle mixture of radiation and convection that changes dramatically between vacuum and pressurized operation. The project model can be used to predict the effectiveness of adding an additional buffer tube to reduce the heat flow from the furnace and the mirror tube temperature. The added buffer tube would be expected to significantly improve the overall performance of the furnace as a means for decreasing the radiated power to the mirror tube.

\section{HIGH TEMPERATURE COMPONENTS AND HEAT CONTAINMENT IMPROVEMENT}

\section{High Temperature Components}

The primary issues that arise when increasing the temperature rating of a multizone transparent furnace above $1000^{\circ} \mathrm{C}$ are: 1) Heater technology, 2) High temperature transparent materials, and 3) Mirror coating technology. Of these, the survival of the mirror coating at high temperature dominated the project effort and will be discussed in the greatest detail. Lower temperature transparent furnaces have been suspect at higher temperatures in general as a result of 1) possible problems with quartz as a material, 2) the temperature limits of the standard nichrome element, and 3) the degradation of the mirror tube coating at elevated temperatures. Earlier attempts to raise furnace temperatures above $1000^{\circ} \mathrm{C}$ have shown that the mirror coating fails, so effort was focused on the mirror tube and its IR reflective coating. Degrading mirror tubes become transparent and emit an excessive amount of heat, requiring unacceptable levels of heater power. The problems of tube and heating element material have relatively simple solutions, whereas improving the mirror tube is more difficult.

\section{Heater Technology}

The first issue has to do with developing new, higher temperature heater technology. Below $1000^{\circ} \mathrm{C}$, standard nickel alloy based-sheathed heaters are typically used in transparent furnaces. In this approach, the heating wire is coaxially drawn inside an Inconel tube with Magnesium Oxide (MgO) insulation between for electrical isolation. The coaxial wire is wound into spiral coils and support rods are brazed to the sheath to hold 
the coils at a specific spacing. The coil spacing is designed to provide a specific temperature profile that has been designed to meet a specific customers requirement. Neither the support rods or the electrical lead wires exiting the furnace cause short circuits since they are electrically isolated from the healer wire by the MgO. Relatively large gaps between the coils provide a view of the material being processed within the furnace core. At higher temperatures nickel alloys cannot be used since their practical temperature limit is exceeded.

In standard (i.e., non-transparent) higher temperature furnaces, the heaters are generally made from uninsulated electrical wire. If the adjacent wires were to touch, short circuits would result, resulting in furnace failure. Therefore, the wires are wound onto grooved tubes so that the wires cannot short circuit. In the case of transparent furnaces, grooved quartz rods are used.

Heating Element The temperature limit of the standard nichrome heating element is avoided by using a kanthal heating element, which is a standard technology. The kanthal element should perform adequately up to about $1300^{\circ} \mathrm{C}$, which is a comfortable temperature limit for a $1200^{\circ} \mathrm{C}$ sample temperature. Kanthal is an alloy consisting of $25 \% \mathrm{Cr}, 3 \% \mathrm{Co}, 5 \% \mathrm{Al}$, with a balance of $\mathrm{Fe}$. Once the surface is oxidized the elements have a emissivity of 0.7 . Kanthal elements are not appropriate for vacuum use because this material requires continuous oxidation to create a refractory surface coating that allows the element to survive. In vacuum or inert gases molybdenum based elements survive to very high temperatures and are the material of choice. These elements are destroyed by high temperature oxidation and cannot be used in air. During furnace experiments the kanthal heating element performed well throughout all of the preliminary high temperature tests. The kanthal element performed without difficulty, and without sagging. Some element distortion occurred at the highest currents during the final feasibility tests and the surface became slightly degraded, but this was expected, considering the $1280^{\circ} \mathrm{C}$ element temperature and high current (about 33A).

\section{High Temperature Transparent Materials}

Transparent furnaces have traditionally been constructed out of quartz tubes. Quartz has a softening point at $1670^{\circ} \mathrm{C}$, an annealing point at $1140^{\circ} \mathrm{C}$, and a strain point $1070^{\circ} \mathrm{C}$. However, quartz is commonly used at temperatures up to $1400^{\circ} \mathrm{C}$ in semiconductor industry, where very clean conditions prevents devitrification and rotation prevents sagging. GAS is grown at $1250^{\circ} \mathrm{C}$.

The problem of quartz as a material is in its sensitivity to chemical attack at higher temperatures, and its slow sagging. Although both of these weaknesses will prevent the use of quartz at temperatures much higher than $1200^{\circ} \mathrm{C}$ it is believed that the performance of quartz is adequate for this project. Chemical attack can be prevented by standardizing cleanliness procedures and pure gases (necessary for proper sample control in any case). Sagging is slow and can be compensated for by rotation of the quartz to prevent significant sagging in any one direction. It is believed that the great additional cost of alternate materials (such as sapphire) outweighs their advantages at the target temperature.

In fact, the quartz furnace elements performed will throughout the high temperature tests. The quartz was apparently unaffected by the $1200^{\circ} \mathrm{C}$ temperatures for 2 days, and post analysis could determine no significant sagging. The kanthal element performed without difficulty, and without sagging. Some element distortion occurred at the highest currents, but this is was expected, considering the $1280^{\circ} \mathrm{C}$ element temperature and high current (about 33A).

Sapphire. The use of alternate materials may be warranted in spite of an increase in price as a result of being able to use stronger or more transparent materials. Sapphire has the great advantage of being able to withstand much higher temperatures than quartz (over $1600^{\circ} \mathrm{C}$ versus 1100 to $1200^{\circ} \mathrm{C}$ ). It is also over a factor of 10 stronger than glass. Sapphire is so strong (410 MPa) that for a sapphire shell of $15 \mathrm{~cm}$ diameter under vacuum the thickness is determined by how thin a piece can be machined (less than a $\mathrm{mm}$ ) rather than as a result of failure stress. Durable gold coatings can easily be produced on sapphire, surviving to at least the temperature limits of similar coatings on quartz. Edge grown sapphire can be produced cheaply, but polishing expense cannot be avoided. Long sapphire tubes can be produced by using a sapphire bonding frit, yielding joined pieces that are functionally the same as the original pieces.

ZnSe. One approach to making a superior mirror tube would be to use an outer shell made of ZnSe with the gold coating on the outside. ZnSe has two advantages over quartz. First, the $\mathrm{ZnSe}$ has a much higher surface reflection (17\% versus $4 \%$ as a result of its higher index of refraction), which means less radiation enters the material. Second, the $\mathrm{ZnSe}$ is transparent out to 20 microns, so that it will not absorb any significant IR radiation 
compared with the quartz. Any absorption would be in the gold coating and binder itself. It is not known how to make a hard gold coating on this material, however. Similar reasoning applies to sapphire, but it is only transparent to 4-5 microns. Because of its relatively low melting point $\mathrm{ZnSe}$ can only be used as an outer tube. It is also expensive to produce.

\section{Mirror Tube Research}

The mirror shell is the element in a transparent furnace that contains the radiant heat. At temperatures of interest for materials processing most of the power of this radiation is in the infrared. The purpose of the mirror shell is to reflect the IR and thus the heat while transmitting visible radiation so that furnace processes can be viewed. High temperature IR reflective coatings that transmit in the visible are usually made from a thin gold film deposited on a quartz substrate using any one of a number of materials to bind the metallic gold to the oxide quartz. As the furnace temperature increases the radiant power increases in proportion to $\mathrm{T}^{4}$, so that optimum function of the mirror tube is imperative. At $800^{\circ} \mathrm{C}$ a $200^{\circ} \mathrm{C}$ temperature increase will double the radiant power output. The immediate object of this project investigation has been to increase the temperature limit of the mirror rube coating so that, together with the kanthal element, the transparent furnace in its present form can be operated at $1200^{\circ} \mathrm{C}$. A secondary task has been to understand the cause of the failure of the present mirror tube coating.

As work on this task has proceeded a number of weaknesses have been found in the current operation of the mirror tube that has diminished its performance. These weaknesses are 1) IR absorption and consequent heating in the quartz itself because the reflective coating is on the outside of the mirror tube for superior coating application, 2) Broadband radiant absorption and heating in the coating itself as a result of an absorptive binder that is used to attach the gold to the quartz, 3) Loss of large areas of the coating beginning at temperatures of above $400^{\circ} \mathrm{C}$ (a temperature reached in the current furnace configuration if the sample temperature is much above $\left.1000^{\circ} \mathrm{C}\right)$.

As previously discussed, the quartz absorbs a significant amount of radiant heat from the hot components at the center of the furnace as a result of its lack of transparency at wavelengths longer than $4 \mu \mathrm{m}$. At temperatures below $800^{\circ} \mathrm{C}$ this radiant heating is not significant because heat transfer in the furnace is dominated by convective heating. At the higher target temperatures of this program, however, this absorption needs to be reduced. Although the simplest solution is to coat the inside of the mirror tube, such coatings are more expensive and tend to give non-uniform thickness. Both of these problems can be avoided by changing the envelope shape from a cylinder to a hexagon, using flat plates that are significantly less expensive to coat than the outside of tubes. Another approach is to use a buffer tube between the inner shield tube and the mirror tube. Such a tube was proposed and used in experiments to give straightforward added thermal insulation just from convective heat transfer. This tube, however, will absorb the IR radiation just as the mirror tube would, but will not reradiate it as much because its temperature is significantly less than that of the inner shield tube. The buffer tube thus acts as a protective radiant heat sink for the mirror tube, eliminating absorption of the IR in the mirror tube and consequent heating and degradation of the coating. If there is sufficient drop in temperature the coating could remain as an outer coating on a tube.

It was known at the beginning of the program that one factor limiting furnace temperature was that the performance and integrity of the mirror tube coating degraded when its temperature increased beyond $400-500^{\circ} \mathrm{C}$. At these temperatures small visible flaws appear in the coating and the radiant confinement decreases. The degradation process continues at a rate determined by the temperature. For borderline temperatures the slow coating degradation is measured by an increase in heater coil temperature that is required to maintain a given temperature over the operating period.

IR Reflective Coating - An assessment of the performance and improvement in the IR reflective gold

coating begins with the historical reason for the composition of the coating. Gold is the traditional material that is used to combine visible transmission with IR reflection. Many other materials have since been used for what are now known as heat reflective windows, and both high visible transmission and near perfect broadband IR reflection have been achieved, driven by the mass market of solar windows. Unfortunately, these materials cannot survive temperatures above a few hundred ${ }^{\circ} \mathrm{C}$ and are thus not candidates for application to transparent furnaces. Also traditional is the use of chromium as a binder for the gold to the quartz, in wide use in the electronics industry [15]. Chromium is used for is excellent binding strength to both quartz and gold, and for its 
coefficient of thermal expansion that is midway between that of quartz and gold, minimizing thermal stress in the coating. The use of chromium is based on electronics applications, however, and not optical applications.

Binder Radiation Absorption - Examination of the reflection/transmission curves of the current transparent furnace mirror tubes shows initially that the reflection is good (over $85 \%$ across the IR spectrum). However, subtraction of the transmission from the reflection curves (and accounting for surface boundary reflections caused by differences in the index of refraction of the materials) as a function of wavelength across the spectrum indicates that the coating has a $10 \%$ absorption. It was initially thought that this was a characteristic of the gold, because the chromium layer was so thin (about 10 Angstroms) that it would not absorb a significant amount of radiation.

The optical behavior of thin films is well understood, however, and the absorption/transmission characteristics of coatings can be predicted theoretically based on published values of $\mathbf{n}$ and $\mathbf{k}$, the real and imaginary parts of the index of refraction of the material [16]. Such a detailed calculation was performed and is presented in Appendix B. It shows that the radiation absorption is not in the gold, but in the chromium. Conversation with commercial coaters indicated that this is generally recognized in the very small optical gold/IR reflective coating business. This absorption can be avoided by facing the gold to the heat source and not using a protective overcoat. One test sample with such a transparent test coating in fact showed a $10 \%$ higher reflectivity with comparable transmission, confirming experimentally that the absorption resuits from the chromium binder.

The absorption can also be reduced by using a different material than chromium. To bind the gold chrome alloys with the gold and forms and oxide alloy with the quartz. The chrome in the gold is itself absorptive, as are most normal metals, but its oxide, $\mathrm{Cr}_{2} \mathrm{O}_{3}$, is particularly absorptive; it is a material known for its broadband, near-perfect absorption. Other materials, such as titanium, form a transparent oxide, but have different problems.

Mirror Tube Improvements There are quite a few possible solutions to the coating problem. The brute force approach is to provide a water cooling jacket to maintain a very low coating temperature. This approach was too complex for Phase I and suffers from all of the problems of sealing a water jacket onto a complex system. Air cooling is also possible and was used in the feasibility experiments discussed below. If a cooling flow is used, a number of factors must be kept in mind. The first is that uniform flow must be maintained around the circumference. This can be done using a high pressure drop manifold that is uniform around the circumference. In the case of water the flow rate should be considerably higher than that calculated, because the basic heat extraction geometry is unstable. If a hot spot develops, the water turns to steam and cuts off further local water flow, leading to less cooling and a runaway temperature locally. The large spot heating will cause large local thermal stresses and break the shell. Water cooling would be used on the outside of the reflective coating itself rather than on the inside of the mirror tube because water absorbs strongly in the IR. The immediate contact with water would keep the coating cool even if the inside of the shell were much warmer. This technique is limited for glass, since a buildup of a thermal gradient through the shell would again cause thermal stresses that would break the glass. Glass has a very low thermal conductivity so this would take a time on the order of minutes, but it failure would occur for inner to outer temperature gradients on the order of 10 's of degrees rather than 100's. In the case of the transparent furnaces discussed in this program the quartz shells are too thin to support dangerous thermal gradients except in extreme cases.

Another approach would be to use an outer shell made of $\mathrm{ZnSe}$ with the gold coating on the outside. $\mathrm{ZnSe}$ has two advantages over quartz. First, the $\mathrm{ZnSe}$ has a much higher surface reflection (17\% versus $4 \%$ as a result of its higher index of refraction), which means less radiation enters the material. Second, the $\mathrm{ZnSe}$ is transparent out to 20 microns, so that it will not absorb any significant IR radiation compared with the quartz. Any absorption would be in the gold coating and binder itself. It is not known how to make a hard gold coating on this material, however. Similar reasoning applies to sapphire, but it is only transparent to 4-5 microns.

A modification to the gold coating that would cut the transmitted radiant power would be to attempt to create more narrow band coatings. One way to do this would be a gold interference filter. The normal constraints of avoiding higher resonances by using blocking material would not be necessary in this case, since the coating is just intended to cut down on the transmission relative to a simple gold coat.

Convective heat losses could be reduced by evacuating the furnace or building an outer mirror shell with 2 layers separated by a vacuum. Another simple solution is to simply increase the size of the mirror tube and thus lower the power deposited per unit area and increase the effectiveness of external cooling. Large, tubes are more expensive but most of the cost is in the coating process, so significant improvements could be made in this way at 
the expense of a more awkward apparatus. This technique would lead to a lower mirror tube temperature, but would not decrease the heat released from the furnace; it would be better to improve the heat rejection.

Gold Coating Failure; Mirror Tube Examination - A few mirror tubes that had been heated to temperatures over $500^{\circ} \mathrm{C}$ previous to this program were available for microscopic study. Inspection of these tubes showed that mirror degradation occurred as a result of spalling of the coating extending slightly into the substrate. The coating did not come off in large patches, but in small pieces of fractions of a mm in diameter. Large areas became transparent when the spalling became widespread in a particular area (Fig. 6). Widely dispersed spalling was visible even in areas that had no apparent degradation (Fig. 7). This coating behavior implies that the coating is failing as a result of thermal stress at the binder interface [17].

Much is known about the strength of thin film coatings [18]. The overall strength of the coating is determined by the binding energy of the materials, their coefficient of thermal expansion, their yield strength, and their failure strength. Ideally the in coefficient of thermal expansion of the substrate and the gold should be identical. Quartz has a very low coefficient of expansion, however, so coatings on its surface tend to buckle. Gold binders reduce stress the most if they have in intermediate coefficient of thermal expansion between the quartz and the gold, and this is the case with chromium. As has been discussed above, metallic binders diffuse away from the interface and thus lose their effectiveness. Gold is also known to agglomerate at high temperatures $[19,20]$. Additional references in the area of thin film gold coatings and their optical properties are also given [21-36].

Many possibilities have been considered as causes for the failure of the coating, but spalling resulting from thermal expansion stress is the most probable candidate. There have been two confusing pieces of past experimental data to explain. One is that optical flats with the same coating as the tubes survive in furnaces at temperatures as high as $700^{\circ} \mathrm{C}$ without degradation, whereas the tubes begin to degrade at $400^{\circ} \mathrm{C}$. Furthermore a competing vendor supplies tubes with similar gold coatings on the inside, and these survive at somewhat higher temperatures. It is now believed that all of this data is consistent with thermal expansion stress failure of the coating. The problem is centered on the peculiar processing the surface of the quartz tubes. Since these tubes are melt formed, the resulting surface finishes are smooth on a microscale. This results in microscopically flat coatings that fail in accordance with thermal expansion stress calculations. The optical flats, however, are ground and polished to a standard 80/50 scratch/dig finish, and are thus not flat on a microscale, allowing the coating to expand without spalling off. The internal coating, although also smooth, experiences compressive rather than tensile stress as the coating expands more than the quartz, and thus fails at a higher temperature. This reasoning will be tested by grinding and polishing, then coating in a standard manner a new set of mirror tubes. It is expected that the coating on these tubes will survive the feasibility demonstration tests when the buffer tube is used.

\section{Mirror Tube Experiments}

Experiments with a core temperature of $1100^{\circ} \mathrm{C}$ using the old-style mirror tubes during the reporting period showed that the mirror tube deteriorates slowly but steadily over a 12 hour period at temperatures much in excess of $500^{\circ} \mathrm{C}$. In this test another already partially deteriorated mirror tube was used as a buffer tube and this mirror tube coating was much less reflective but kept the same degradation patterning from previous experiments. This tube was operated at much higher temperatures $\left(700-800^{\circ} \mathrm{C}\right)$. Another mirror tube was operated at temperatures over $1100^{\circ} \mathrm{C}$, and patterning remains. This is apparently a result of diffusion of the chromium (and possibly gold) into the quartz, leading to the extreme stability of the pattern at high temperatures. This effect will be investigated in a follow-on project.

Research into the problem of mirror degradation has been described above. A solution proposed by a coating vendor was to use an oxide binder for the gold that would not absorb thermal radiation and would be stable to higher temperatures than the present coating. This would lead not only to a lower mirror temperature for equivalent conditions where the mirror tube degraded previously, but to stable performance at higher temperatures using the new coating. Another problem that the new coating would solve is metal diffusion of the binder into the gold. It is believed that this diffusion is the cause of the coating degradation in the standard furnace over the 


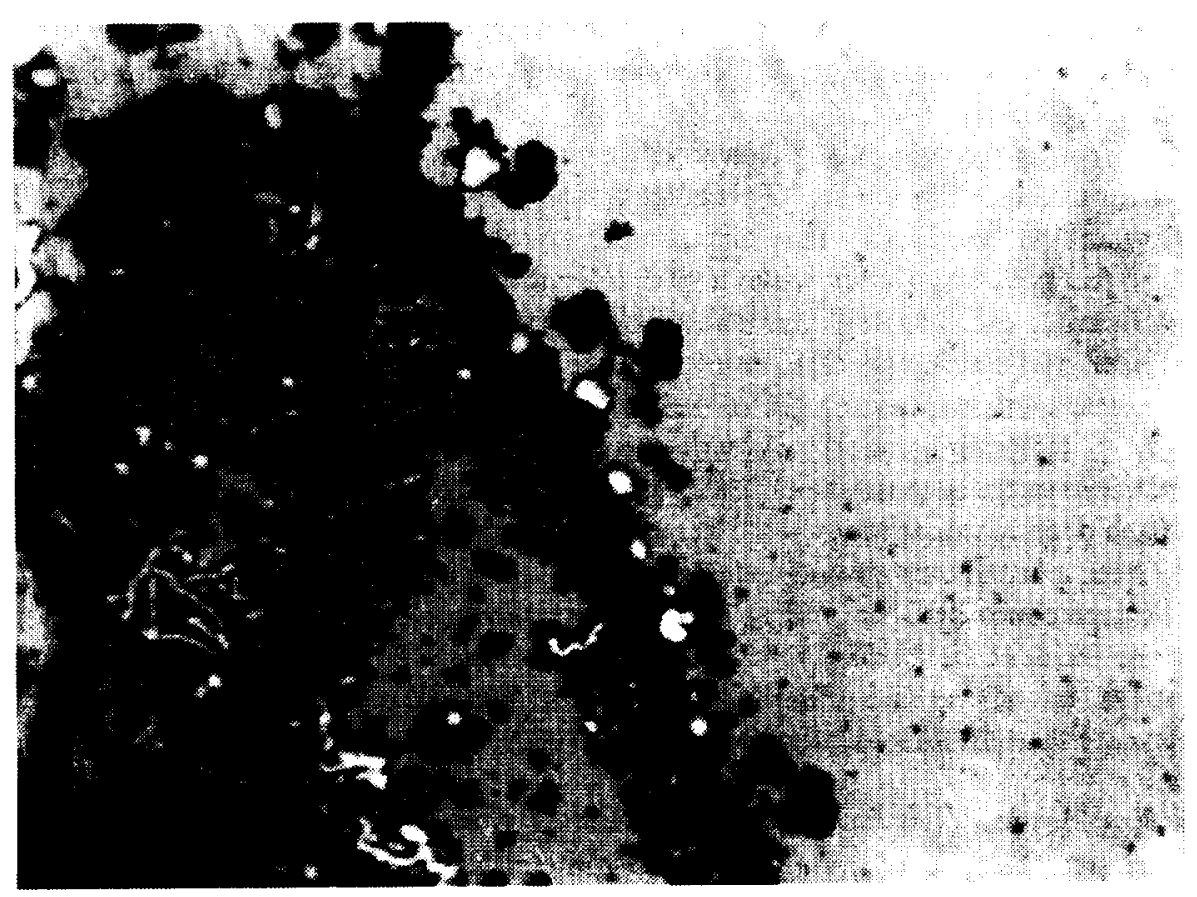

Figure 6. General coating failure near a scratch $(400 x)$.

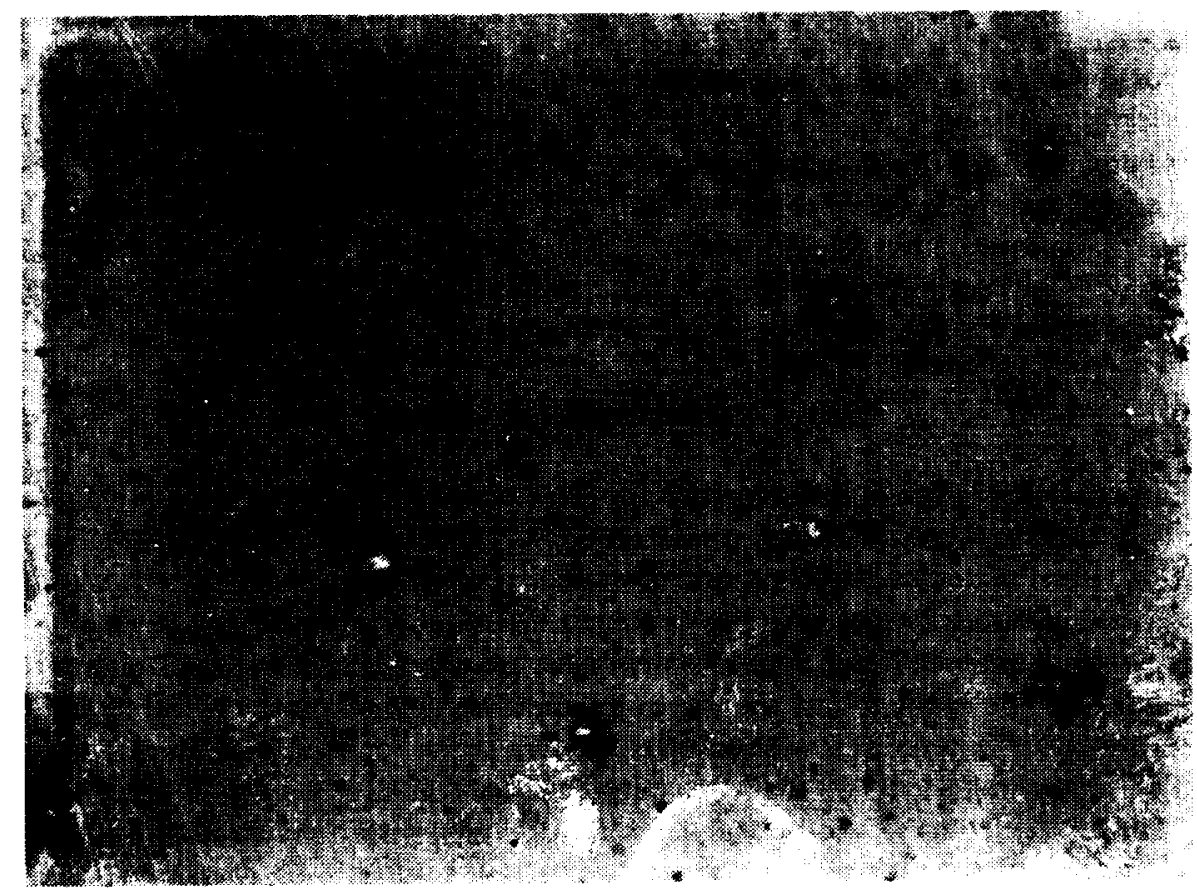

Figure 7. Dispersed coating failure as a result of spalling (200x). 
period of 10 days at high temperatures; when the chromium binder diffuses into the gold, binder strength decreases, and the coating spalls off.

New Mirror Coating Experiments Twelve quartz plates were gold coated by the GM Coating Labs for the final transparent furnace feasibility tests. This coating was claimed to function well at high temperature because the binder was oxide based rather than metallic and was not absorptive. Metallic binders such as were being used initially in this program are known to absorb a significant amount of radiant heat throughout the spectrum. In a simultaneous effort to begin an investigation of $\mathrm{ZnSe} I R$ mirrors, a $2.5 \mathrm{~cm}$ diam., $1 \mathrm{~mm}$ thick disc was included in the new gold coating process.

In furnace experiments the coating performed worse that the chromium-gold mirror coating, failing rapidly in the $400-500^{\circ} \mathrm{C}$ temperature range. As with the standard gold coating, the exact temperature where the coating fails is impossible to fix because the failure is gradual, the temperatures non-uniform and fluctuating in time. Not only did the coating fail at lower temperatures, it also failed in a more destructive manner - the gold coating disappeared over a broad area simultaneously. This is dangerous because it rapidly leads to an unstable feedback with the furnace controller: the coating failure causes more power to be fed to the heater coil, which causes more heat to be incident on the coating and more degradation. The chromium bound coating does not fail rapidly over large areas, but slowly and progressively spalls off in small pieces. Some of the coating survives to much higher temperature than the first small areas that come off. This is true of the oxide coating also, but to a much lesser degree.

The coating vendor was consulted, and stated that the coating was known to survive at $450^{\circ} \mathrm{C}$, and unknown at higher temperatures. The coating is not absorptive in the IR only when the gold side faces the heat source; facing away from the source the binder absorbs across the radiating spectrum. The binder is matched with the gold for maximum transmission at visible wavelengths. Having the gold facing the heat source was attempted in the furnace, but at core temperatures over $1000^{\circ} \mathrm{C}$ the inner faces of the plates were hotter than $500^{\circ} \mathrm{C}$ as a result of convection heating, and thus could not be used in this configuration. Reassembly of the furnace with the gold facing out allowed the coating to be cooled to low temperatures as described below, leading to excellent coating performance and furnace stability at $1100^{\circ} \mathrm{C}$ core temperature. Unfortunately hot indoor summer temperatures combined with a coating degradation temperature that was lower as a result of absorption in the binder (degradation observed at about $400^{\circ} \mathrm{C}$ ) caused a slow deterioration of the coating and furnace performance at $1200^{\circ} \mathrm{C}$ core temperature.

It is concluded that the oxide coating is inferior to the standard chromium-gold coating as an external coating in this application. The performance of the standard coating is also significantly worse as an outer coating on the quartz tubes being used for this program when compared with its use as an internal coating or on a flat plate. Flat plate coatings have been shown to survive to $700^{\circ} \mathrm{C}$ in a furnace by Insight Scientific. The project experiments using such plates would have easily enabled stable operation at $1200^{\circ} \mathrm{C}$.

Discussions with the coating vendor indicate that there are avenues to improve the high temperature capabilities of IR mirrors that are transparent at visible wavelengths.

\section{Heat Containment Improvement}

A major furnace design issue is that the relatively large power requirement of bigh temperature transparent furnaces must be reduced. The high power required results in mirror tube surface temperatures at or above $400^{\circ} \mathrm{C}$ in air, which is not practical for routine operation. Thermal energy released by the furnace is not tolerable in space based operations or in a laboratory on earth where it can provide enough heating to prevent work nearby. Furthermore, multi-kilowatt power requirements are unacceptable for space operation. It is planned to address this question in the follow-on project by improving the efficiency of the radiation containment and by eliminating convective heat transfer with an outer vacuum jacket. It should be noted that in terms of heat transfer a factor of 10 reduction in pressure is adequate insulation and an easy vacuum to obtain.

Heat containment can be improved by making the muffle tube absorb radiation across the spectrum. This would concentrate the radiative heat at the center of the furnace rather than having it undergo multiple reflections and be lost out the ends. There is more than enough visible radiation emitted by the coil at high temperature to be able to view the sample. Typical gold coatings are less than $10 \%$ transmissive, and there is easy visibility above $800^{\circ} \mathrm{C}$. Another possibility is radiation containment at the furnace ends. 


\section{TEMPERATURE PROFILE DESIGN}

Work on this task takes advantage of the extensive work performed by Insight Scientific in the design, construction and optimization of transparent furnaces. At present detailed multizone temperature control designs are subcontracted to companies that specialize in furnace computations. These computations will have to be modified if, as planned, the IR containment is significantly improved for this program. Detailed multizone designs are less important for the demonstration of transparent furnace operation at $1200^{\circ} \mathrm{C}$, however, so that work in the project has concentrated on the other tasks. Work in this area has been summarized in terms of simple sets of basic design rules.

There are three basic types of furnace designs that have been considered: a 1 zone constant gradient not adjustable, a 2 zone constant gradient, and a 3 zone profile if no derivative equal to 0 is required. These are discussed below.

\section{Isothermal Profiles}

One heating element is required; two may be used if coil spacing rules are followed.

\section{Coil Spacing Rules:}

1. The spacing of the coils at the ends of the furnace should be 1/2 the spacing at the center.

2. Coil spacing at the center should not exceed $1.3 \mathrm{~cm}$ (center-to-center) for $0.32 \mathrm{~cm}$ diameter wire.

3. If coil spacing exceeds $1.3 \mathrm{~cm}$, thermal "striping" can occur (i.e., "swirling" isotherms).

4. Coil spacing at the center should not exceed $1.9 \mathrm{~cm}$ for $0.48 \mathrm{~cm}$ diameter wire.

5. Four tightly spaced coils are necessary at the end of the heater to bring the temperature up to the isothermal core region temperature.

6. Five coils will create a bump.

7. Three coils will decrease the isothermal length but can be used if the length of the furnace is limited.

\section{Constant gradient profiles}

Coil spacing rules above apply.

\section{Single zone design:}

1. A constant gradient can be obtained with one zone.

2. The slope of constant gradients obtained with one zone are not adjustable.

3. It is impossible to precisely predict the slope a given coil design will provide.

4. Gradient requirements specified by a customer will always change with time, so if a gradient profile is required, two coils should be used.

5. The slope of the gradient is primarily driven by the difference in the coil spacing at the two ends of the coil.

6. The coil spacing in the middle is of secondary importance.

\section{Two zone design:}

1. Two zones provide adjustable constant gradients.

2. The interface between the two zones should be in the center of the gradient region.

3. Coil spacing at the center should be constant.

4. The discontinuity in the coil spacing of the two elements in the middle should be minimized.

5. Two heater leads (one from each element) should extend out from each end cap.

Constant gradient profiles are not very difficult to achieve if the tolerances on the constancy of the slope are not severe. 


\section{Non-constant gradient profiles}

Coil spacing rules apply

The detailed requirements for a non-constant temperature gradient tend to be difficult to specify by the customer, often leading to a changing design constraints. Non-constant profiles are usually twice as time consuming and expensive as initial estimates predict.

Isothermal plateaus adjacent to sharp gradients are very difficult to achieve. The most difficult problem is in the region where the slope changes. It is critical to know if the furnace will be run horizontally or vertically, since a profile developed for horizontal operation will change if the furnace is rotated to the vertical.

\section{HIGH TEMPERATURE TRANSPARENT FURNACE FEASIBILITY}

\section{Transparent Furnace Experiments}

A series of experiments were performed to explore the high temperature limits of the current and new configurations of the transparent furnace. During these experiments power supply instability problems were overcome as were power measurement problems. Power measurement using SCR phase angle controlled supplies is difficult because of the unusual nature of the current waveform. Radiant power measurements were also made with the meter purchased for the program.

Furnace operation was typically performed at progressively higher temperatures to measure the radial temperature profile inside the furnace and the mirror surface temperature as a function of core temperature. Except for the air gap used in the final experiments, the end gaps between adjacent cylinders were packed with alumina felt insulation to minimize heat losses through the ends. A small hole was left in each packing at one end to permit the internal surface of each shell to be measured. This was done by inserting a thin gauge sheathed type $\mathrm{K}$ thermocouple with a handheld thermocouple monitor readout. Internal surface temperatures could be measured in this way, but were sometimes distorted by contact with the opposite surface as a result of the small radial clearances between tubes. The handheld unit also allowed measurement of coil temperature because it is ungrounded.

1) Standard Configuration and Component Experiments - Initial experiments using a variac to supply the heater current were done to explore the low (relatively) temperature behavior of the standard furnace configuration (Fig. 8). The transparent furnace was made up of cylindrical quartz tubes in order of increasing diameter: 1) an inner muffle tube with 3 slotted quartz rods attached with fused quartz, 2) a kanthal heating element wound in the slots, 3) a quartz inner shield tube, and 4) a partially degraded mirror tube. The furnace is mounted in a cradle with half-circle fiber ceramic end supports. Tests were done at furnace core temperatures up to $600^{\circ} \mathrm{C}$ to practice operating the furnace, take measurements for comparison with modeling, and assess the temperature differences between the quartz shells. The variac, rated at $10 \mathrm{~A}$, was run safely at over $13 \mathrm{~A}$ as a result of an understanding of transformer operation and specification.

The next series of experiments tested the temperature limits of stable operation for this standard configuration. For higher current tests a Eurotherm controller and SCR current supply allowed temperature feedback control for supply currents up to $30 \mathrm{~A}$ at $120 \mathrm{VAC}$. Core temperatures up to $900^{\circ} \mathrm{C}$ were achieved, measuring shell and coil temperatures. Radiant power was also measured. Higher core temperatures were not attempted because the external mirror tube temperature reached $550^{\circ} \mathrm{C}$ and the mirror coating was degrading rapidly. These results were consistent with Insight Scientific's previous experience; they were able to obtain $950^{\circ} \mathrm{C}$ using new mirror tubes with very slow degradation over 10 days. This has been the previous limit to practical furnace operating temperature.

2) Buffer Tube Experiments - A larger diameter mirror tube was next added outside the standard configuration. The inner mirror tube then functions less as a mirror tube than a thermally insulating buffer tube between the high temperature inner assembly surrounding the coil and the mirror tube. This buffer tube adds another effective gas insulating layer, and since its temperature is a few hundred degrees $C$ lower than the shield tube, it significantly decreases the long wavelength thermal radiation transmitted to the mirror tube. At the time no clear quartz tube of the proper dimensions was available, and assembly was simpler. The larger mirror tube which then formed the outer furnace shell had been degraded in previous experiments before this 


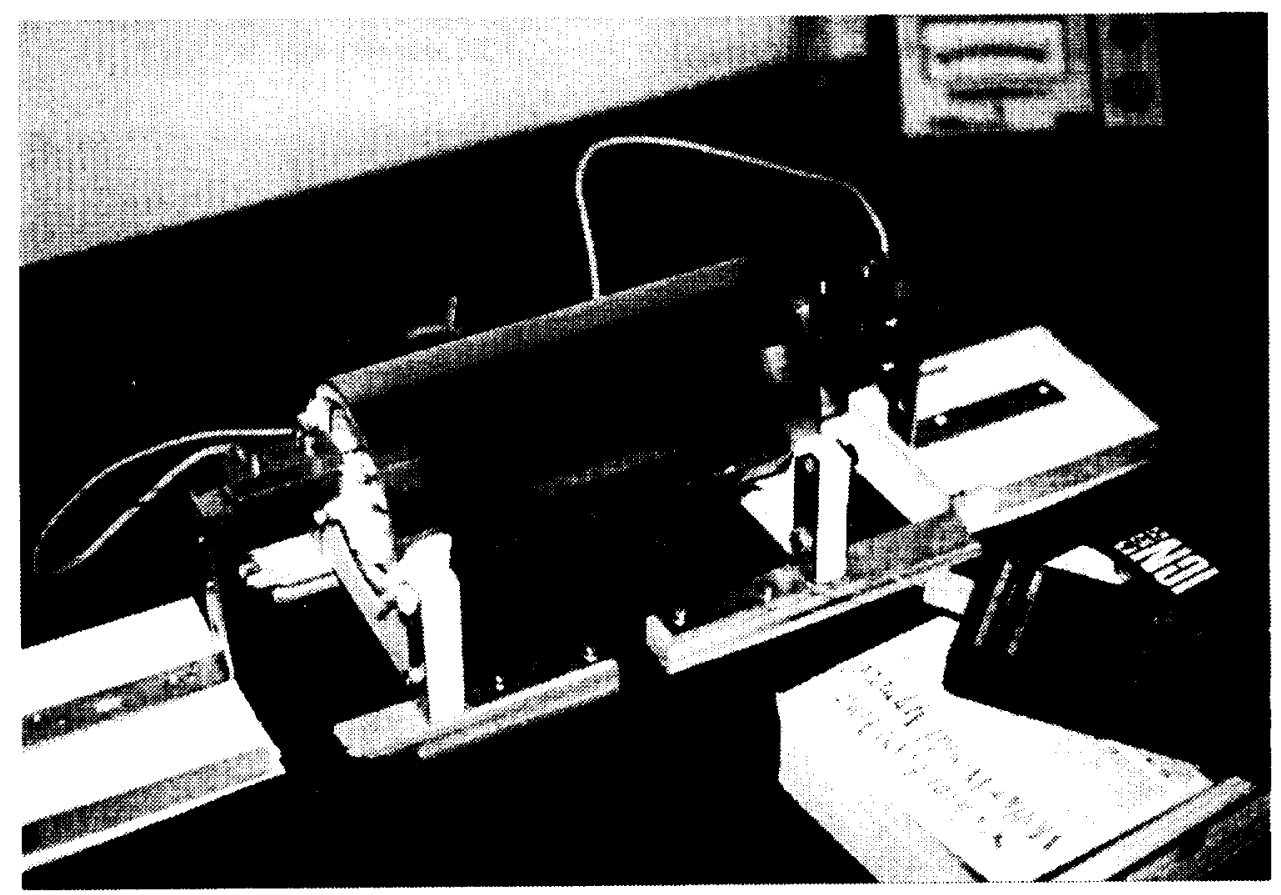

Figure 8. Photograph of the standard configuration transparent furnace used for initial tests.

program by Insight Scientific.

The core temperature was increased in steps as usual, monitoring the radial temperature profile and the external surface temperature, and watching for degradation. At a core temperature of $900^{\circ} \mathrm{C}$ the outside of the mirror tube was at $330^{\circ} \mathrm{C}$ at the side; at $1000^{\circ} \mathrm{C}$ the outside temperature increased to $375^{\circ} \mathrm{C}$, and at $1100^{\circ} \mathrm{C}$ it increased to $525^{\circ} \mathrm{C}$. This configuration was operated at $1000^{\circ} \mathrm{C}$ for 20 hours with a slight increase in power, probably as a result of degradation of the inner mirror tube. The core temperature was then raised to $1100^{\circ} \mathrm{C}$ and held there for 12 hours. During this time the required power steadily increased and the outer mirror coating seemed to be degrading slowly. Operation was terminated when the outer surface reached $590^{\circ} \mathrm{C}$ and it was clear that the degradation was continuing and worsening in an unstable combination with the increasing power demand.

3) Buffer Tube and New Mirror Tube Coating Experiments - After the above tests 12 plates gold coated using the new binder arrived. A platinum-rhenium thermocouple was also obtained to measure the expected $1200^{\circ} \mathrm{C}$ core temperature, as opposed to the Type $\mathrm{K}$ thermocouples that had been used. Since the new coating was supposedly a high temperature coating the furnace was assembled with the standard core, a clear buffer tube (newly obtained) surrounding this, and finally 6 mirror plates arranged in a hexagon as the IR containment mirror tube. A muffin fan was added to increase external cooling beyond natural convection. The gold coating was on the outside to mimic the configuration of the standard mirror tubes.

The core temperature was increased to $800^{\circ} \mathrm{C}$ and held for temperature profile measurements (Fig. 9). Spots became visible in the coating, and since the outside peak temperature was only $330^{\circ} \mathrm{C}$ it was believed that these spots were characteristics of the coating that appeared when the coil got brighter. The coating was only $10 \%$ transparent, so visibility increases in general at higher temperatures. The core temperature was increased to $900^{\circ} \mathrm{C}$, measured radiant power increased, and larger faintly brighter areas began to appear on some plates. The temperature was further increased to $1000^{\circ} \mathrm{C}$ and the outer mirror surfaces were found to be at $500^{\circ} \mathrm{C}$. A this time the radiant power meter showed a factor of 2 increase in a brighter area, and the plate temperature was found to be $130^{\circ} \mathrm{C}$ cooler in an area that was not as bright, so it became clear that the coating was failing. Operation was halted to assess the situation.

It was clear at this point in the experiments that the mirror plates had a similar temperature limit to the standard mirror coating, and that they were not superior in temperature performance (temperature numbers were 
not supplied by the vendor). The object then became to decrease the mirror tube temperature during operation. To do this 4 more clear quartz buffer tubes were added to the original core ( 6 total) as added

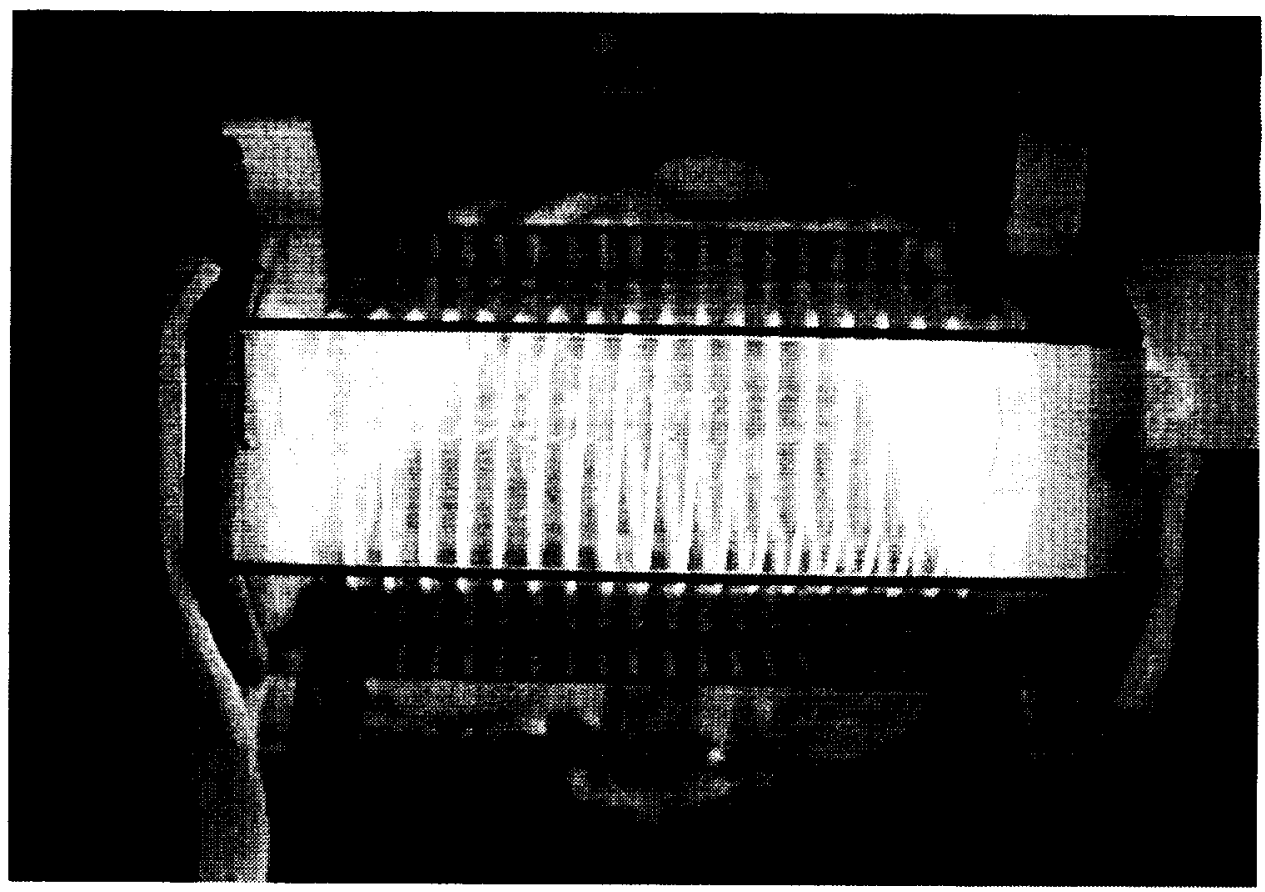

Figure 9. Photograph of transparent furnace with buffer tube and hexagonal mirror tube operating at $800^{\circ} \mathrm{C}$.

insulation, and the mirror plates added as an octagon on the outside of this assembly using 6 new plates and 2 that had experienced the least degradation from previous operation in the hexagonal configuration. The gold coating was placed on the inside to reflect the maximum amount of radiation, while radiant cooling from the quartz outside was to provide extra cooling. The alumina felt between the apexes of the octagon and the adjacent buffer tube was removed to allow the hot gas between the surfaces to escape.

In this configuration the core temperature was increased to $800^{\circ} \mathrm{C}$, at which time the mirror surface temperature was found to be $420^{\circ} \mathrm{C}$. The surface was also scratched in the act of measurement, so it soft and close to failure. A fan blowing at the end did not significant reduce the surface temperature. The outside of the outer quartz tube was found to be at $535^{\circ} \mathrm{C}$, and thus the extra buffer tubes were not adding a large amount of insulating effect. Furnace operation was terminated to try another configuration. No coating degradation was experienced.

\section{Feasibility Demonstration Experiments}

Feasibility experiments were performed in a final assembly that used 3 innovations compared with the furnace built in its standard geometry. In order of importance these innovations were 1 ) The addition of outer quartz shells that were mounted with an open gap between them to allow air flow between these concentric cylinders, 2) The use of quartz buffer tubes for additional thermal insulation between the furnace core and the mirror tube, 3) The use of mirror tubes as buffer tubes such that the mirror coatings after degradation would function as absorbers for reflected heat radiation. These experiments were almost entirely successful in spite of the new mirror coatings that turned out to be worse than those in use in the current furnace.

The furnace was operated at $1100^{\circ} \mathrm{C}$ core temperature for 100 hours at a stable power level, and near $1200^{\circ} \mathrm{C}$ for 50 hours with slight but steady deterioration of the outer mirror coating and slowly increasing power levels. The furnace was operated at $1200^{\circ} \mathrm{C}$ for 24 hours, then the power level was fixed and the core temperature allowed to drift. After 26 more hours of operation the core temperature had drifted to $1180^{\circ} \mathrm{C}$. 
The furnace was assembled based on the recognition that the mirror coatings could not survive the temperatures on the outside of the outer quartz shell that result from a $1200^{\circ} \mathrm{C}$ core temperature, assuming an uncooled transparent furnace that uses clear quartz tubes with air gap insulation. The goal of the assembly was then to achieve maximum cooling on the mirror surface with minimal heat transfer to the mirror shell. Three small muffin fans directed at the mirror surfaces provided the forced-air cooling on all of the external mirror surfaces to keep their temperature to a minimum. Heat transfer was enhanced by the fact that the coating external surface was gold with high thermal conductivity, rather than the more traditional glass overcoat. One of the fans was directed at the end of the furnace to force air through the gap between the outer shells and reduce the heat load entering the outer shell that supports the mirrors. The furnace geometry is shown in Fig. 10. A photograph of the assembly is shown in Fig. 11.

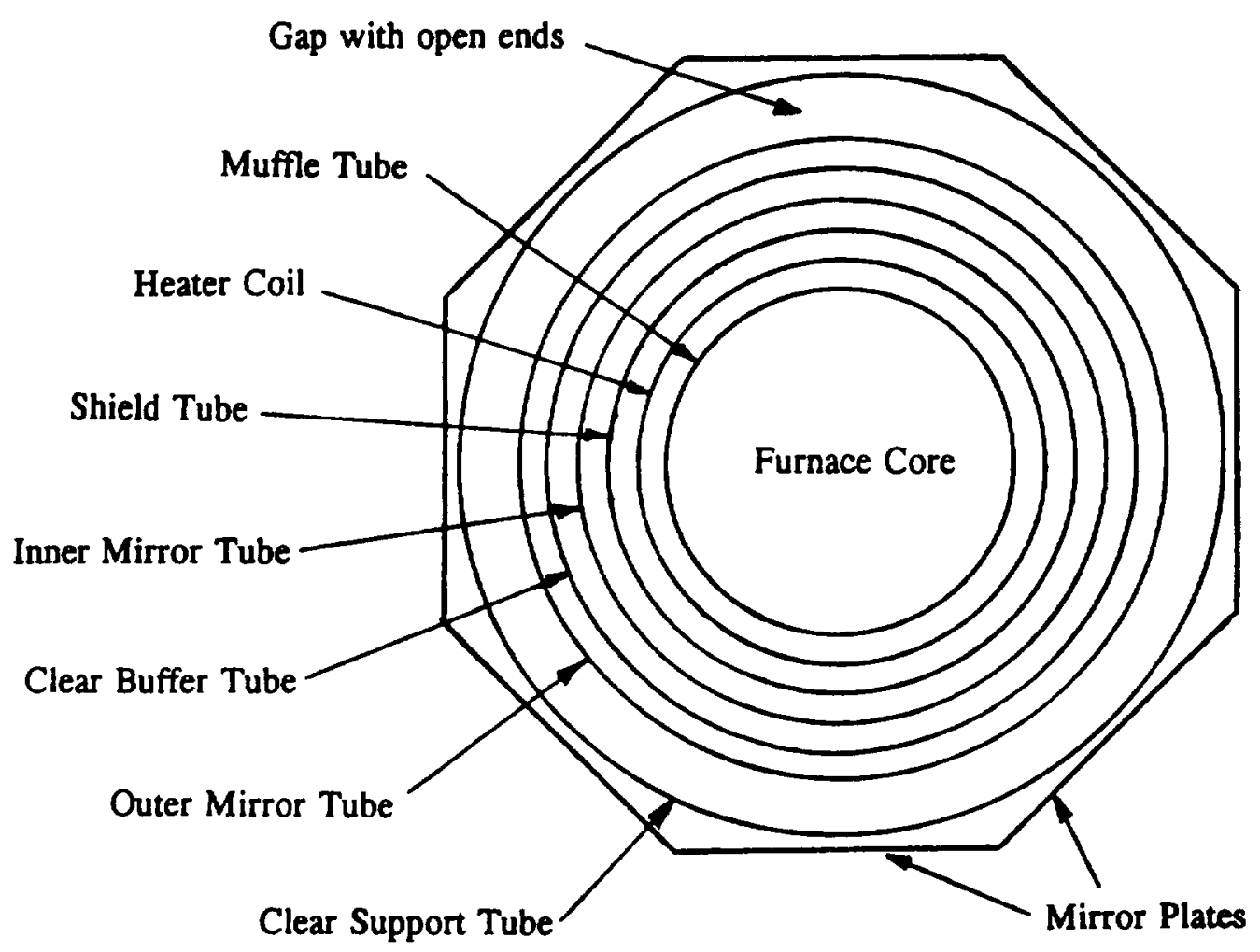

Figure 10. Transparent furnace configuration for feasibility experiments.

Two mirror tubes were inserted into this assembly with the understanding that the mirror coatings would disappear, but some metal would be absorbed into the quartz and act as a radiant heat sink, preventing some of this heat from reaching the mirror tube. This technique was suggested by earlier experiments that showed that clear quartz tubes reduced the heat transfer less than the degraded mirror tubes. Analysis will show how large an effect this was.

The temperature versus time history of the furnace during the feasibility experiments is shown in Fig. 12 . The first test of performance was at a core temperature of $1000^{\circ} \mathrm{C}$ (measured with a platinum-rhenium thermocouple attached to the furnace controller). In this test one fan was blowing at the furnace end to drive air flow between the open gap between outer tubes. The resulting external mirror surface temperatures varied from $40^{\circ} \mathrm{C}$ to $160^{\circ} \mathrm{C}$. The furnace was operated for 19 hours to assure power stability and no deterioration of the coatings. The temperature was next ramped to $1100^{\circ} \mathrm{C}$, and 2 additional fans were added for more direct surface cooling from each side of the furnace at $45^{\circ}$ to induce flows in the same direction as the fan blowing through the end. At $1100^{\circ} \mathrm{C}$ mirror surface temperatures ranged from $85^{\circ} \mathrm{C}$ to $180^{\circ} \mathrm{C}$.

Operation was again continued until power stability was reached. Reaching stability was a somewhat slow process because stability could only occur after the coatings on the inner mirror tubes completed their slow 
degradation to their final burned-in state. At each higher level of core temperature further degradation was observed on the outer mirror tube, accounting for the slow stabilization even when the outer flat mirrors were not degrading. Operation at $1100^{\circ} \mathrm{C}$ was continued after stabilization for a total of 48 hours after $1100^{\circ} \mathrm{C}$ was initially reached as a certain demonstration of feasibility at that temperature in case the furnace could not survive the next step to $1200^{\circ} \mathrm{C}$.

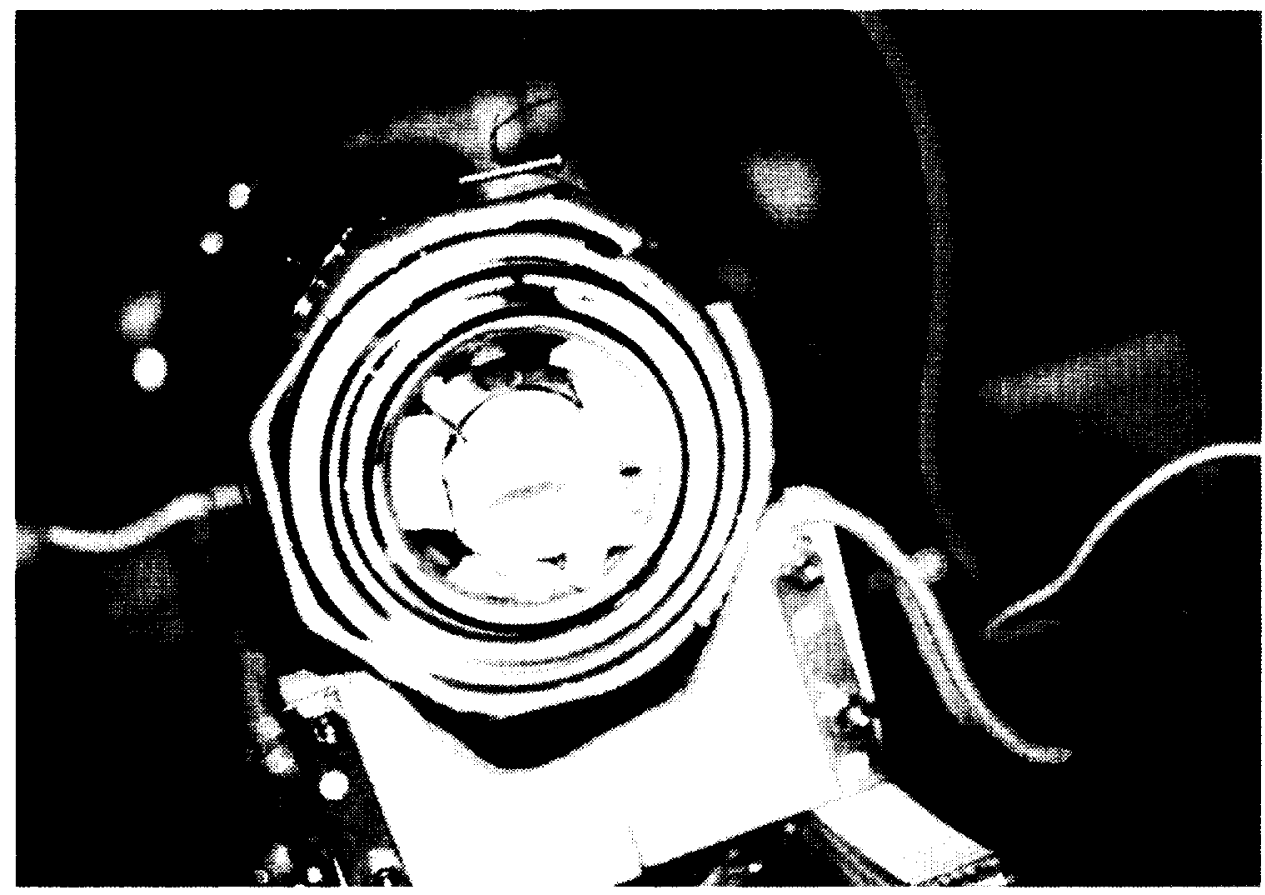

Figure 11. Photograph of final transparent furnace assembly without insulation removed to create a cooling air gap.

The core temperature was then raised to $1200^{\circ} \mathrm{C}$ and maintained. Power levels steadily and slowly increased as at $1100^{\circ} \mathrm{C}$, but were now approaching the limit of the coil and power supply. Outer mirror temperatures of $350^{\circ} \mathrm{C}$ were measured. This was apparently near their operating limit with the coating facing outward, since degradation began to be apparent by small bright holes appearing in some areas of the mirrors, and application defects near the edges. Two of the octagonal mirrors had been partially degraded from previous experiments, and this raised the heat flux necessary for $1200^{\circ} \mathrm{C}$ operation also. Room temperatures from $80-90^{\circ} \mathrm{F}$ also caused increases in the required power.

After 24 hours of operation at $1200^{\circ} \mathrm{C}$ with feedback control and slowly increasing power demand, it was decided to fix the power and observe the core temperature. The mirror coatings were slowly but definitely deteriorating in some areas near the center where end cooling was less important. In another 26 hours the temperature drifted from 1200 to $1180^{\circ} \mathrm{C}$. The mirrors were clearly slowly degrading, which was causing the power demand increase. At this time the power was slightly increased, raising the temperature to $1187^{\circ} \mathrm{C}$, but coil distortion began to be observed, so no further operation at this power level was attempted.

The core temperature was then decreased to $1100^{\circ} \mathrm{C}$ and stable operation again demonstrated, continuing operation until a 100 hour demonstration period was completed. As expected the mirrors stabilized at the lower temperatures and no delay for stabilization was observed, since the inner mirror tubes were already burned-in. Total operating time at high temperature was 172 hours.

It is unfortunate that this demonstration was performed during the summer, since a cooler environment would definitely led to stable operation at $1200^{\circ} \mathrm{C}$. This was demonstrated a number of times during operation. During constant power operation the room temperature increased steadily overnight with the doors closed and with a limited amount of fan cooling. When supervised the garage door near the furnace was open, cooling the entire room with cross flow from a window fan in an opposite door. In one case when the room was shut the 
inside temperature increased from $79^{\circ} \mathrm{F}$ to $83^{\circ} \mathrm{F}$ and the furnace core temperature decreased from $1194^{\circ} \mathrm{C}$ to $1188^{\circ} \mathrm{C}$. A decrease in temperature from $79^{\circ} \mathrm{F}$ to $77^{\circ} \mathrm{C}$ resulted in an increase in core temperature from $1175^{\circ} \mathrm{C}$ to $1185^{\circ} \mathrm{C}$. There is a strong dependence of core temperature on absolute room temperature. A test of coating temperature (core temp $=1100^{\circ} \mathrm{C}$ ) showed that a room temperature change from $78^{\circ} \mathrm{F}$ to $76^{\circ} \mathrm{C}$ caused a surface temperature change from $104^{\circ} \mathrm{C}$ to $86^{\circ} \mathrm{C}$. This effect is larger for higher surface temperatures; a change in room temperature from $79^{\circ} \mathrm{F}$ to $77^{\circ} \mathrm{C}$ caused a surface temperature change from $215^{\circ} \mathrm{C}$ to $186^{\circ} \mathrm{C}$. Winter operation would have led to mirror surface temperatures low enough to prevent mirror degradation for

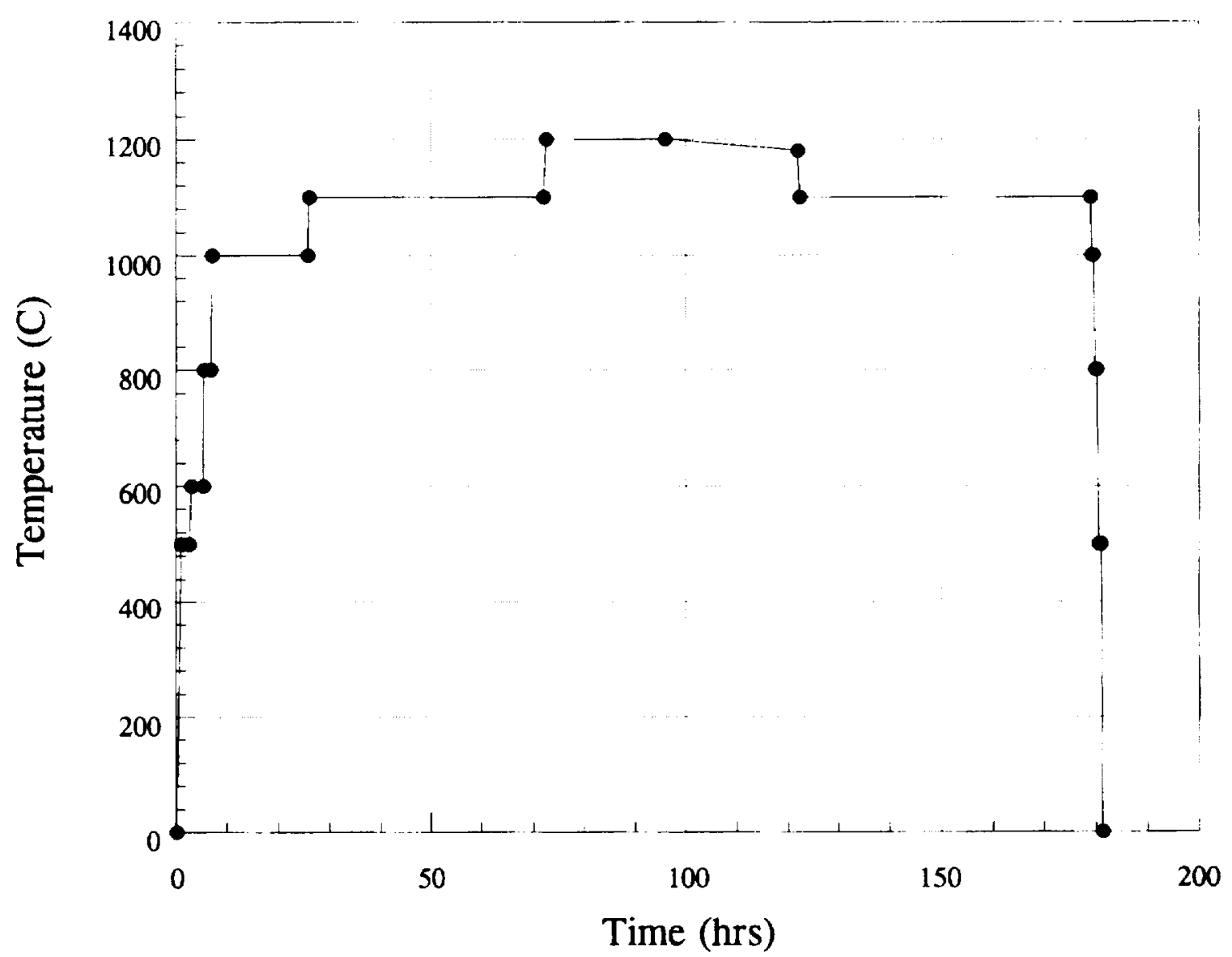

Figure 12. Time history of transparent furnace core temperature during feasibility experiments.

core temperatures of $1200^{\circ} \mathrm{C}$ and thus stable operation for indefinite periods at this temperature, even for the inferior mirror coating.

The choice of introducing cooling to minimize mirror temperature was taken with the understanding that this would increase the power required to operate at a given temperature. This also makes higher temperature operation more difficult, since the power required (over $3 \mathrm{kw}$ ) increases more rapidly than for uncooled operation and increases the heat fluxes at the mirror surface. This effect contributed to the mirror degradation and the approach to the limit of the heater coils. Using a muffle tube that absorbs radiation and vacuum insulation between the outer shells cooling will radically reduce power requirements in the follow-on project.

\section{Furnace Operation Analysis}

Extensive temperature and power data was taken for all of the experiments discussed above. Radial temperature profiles at the surfaces of the furnace tubes are shown in Fig. 13 for operation at 1000, 1100, and 
$1200^{\circ} \mathrm{C}$. Data points in parenthesis are projected on the basis of lower temperature measurements. Temperature measurements near $1200^{\circ} \mathrm{C}$ could not reliably be made by the Type $\mathrm{K}$ handheld thermometer that was used. The radial profiles show a steady drop in temperature away from the furnace core. As the core temperature increases the temperature drop in the air gap increases. The outer temperatures are averages of the various plate temperatures, since they vary from face to face and axially in temperature.

The axial variation in temperature of the inside top of the outer quartz tube that supports the mirror plates is shown in Fig. 14. This plot shows that the cooling velocity between the tubes was not adequate to cool the end of the downstream end of the furnace. It is noted that the safe temperature for mirror operation is below $400^{\circ} \mathrm{C}$, and there is an additional heat input to the mirrors from absorbed radiation. In fact the mirror coating on some of the plates failed at the end, and the lack of cooling at the end was a major contributing factor leading to unstable operation at $1200^{\circ} \mathrm{C}$. Adequate cooling would have shown a slow linear increase in

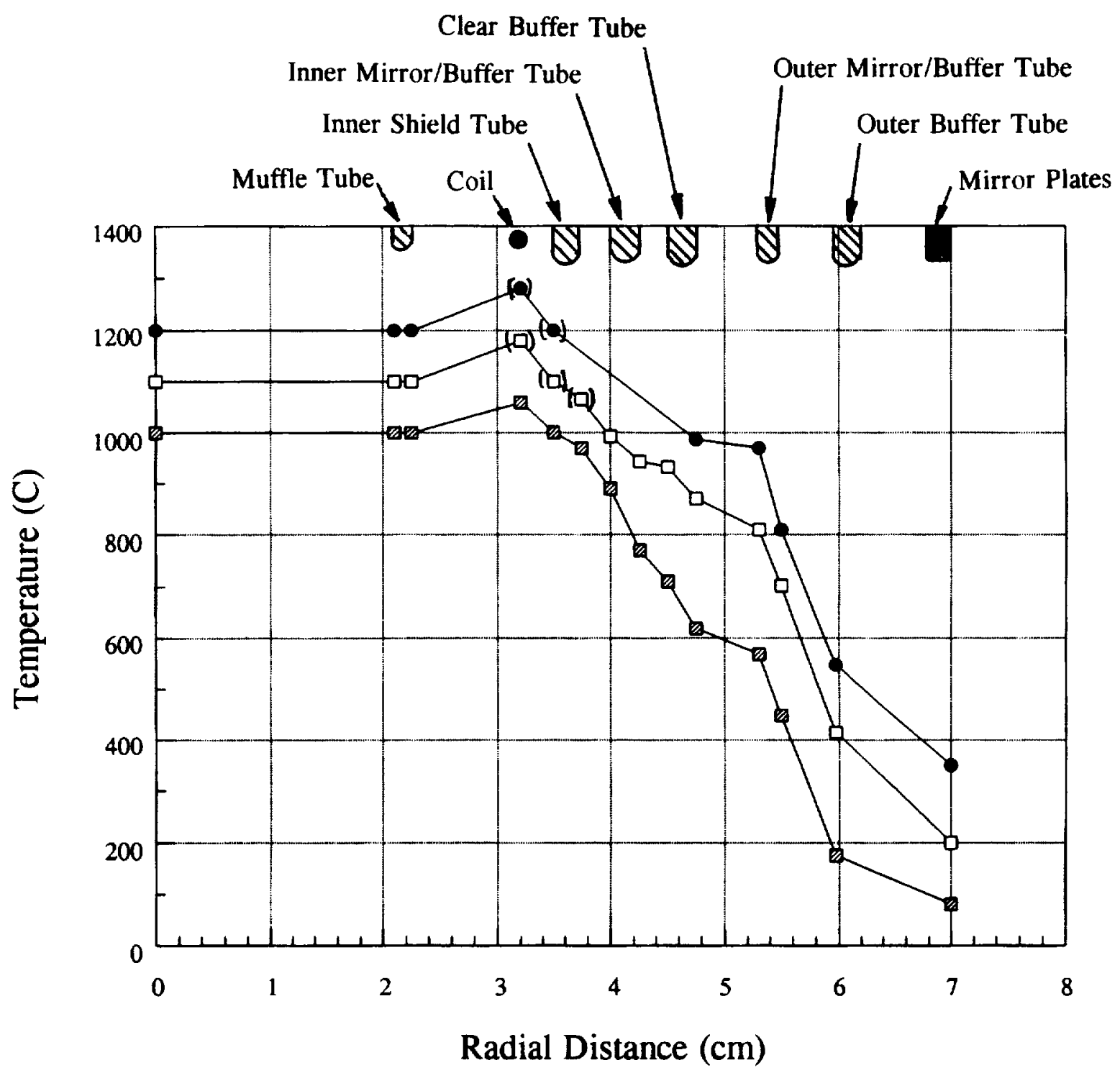

Figure 13. Radial temperature profiles at the furnace quartz surfaces for high temperature operation. 
temperature rather than the asymptotic behavior seen.

Furnace power data is shown in Fig. 15, together with the temperature/time history of high temperature operation and room temperature measurements. Room temperature measurements are included in the data because of the dependence of power ambient temperature as discussed above. The power levels required for furnace operation at 1000,1100 , and $1200^{\circ} \mathrm{C}$ are shown and given in Table 3 below. At 1000 and $1100^{\circ} \mathrm{C}$ furnace operation is stable in power, varying slightly in response to changes in feedback control and room temperature changes. Room heating as a result of furnace operation is seen, as is a corresponding rise in required power. The slight increase in final power at $1100^{\circ} \mathrm{C}$ is cause by an increase in room temperature. The increase in power required for operation at $1100^{\circ} \mathrm{C}$ in final testing is a direct result of partial mirror degradation, but the power is still stable because mirror temperatures have been lowered enough to prevent further degradation. The constant power shown at $1200^{\circ} \mathrm{C}$ occurs because temperature feedback has been discontinued and the core temperature is slowly decreasing (about $20^{\circ} \mathrm{C}$ in 26 hours). The power was fixed to prevent coil degradation.

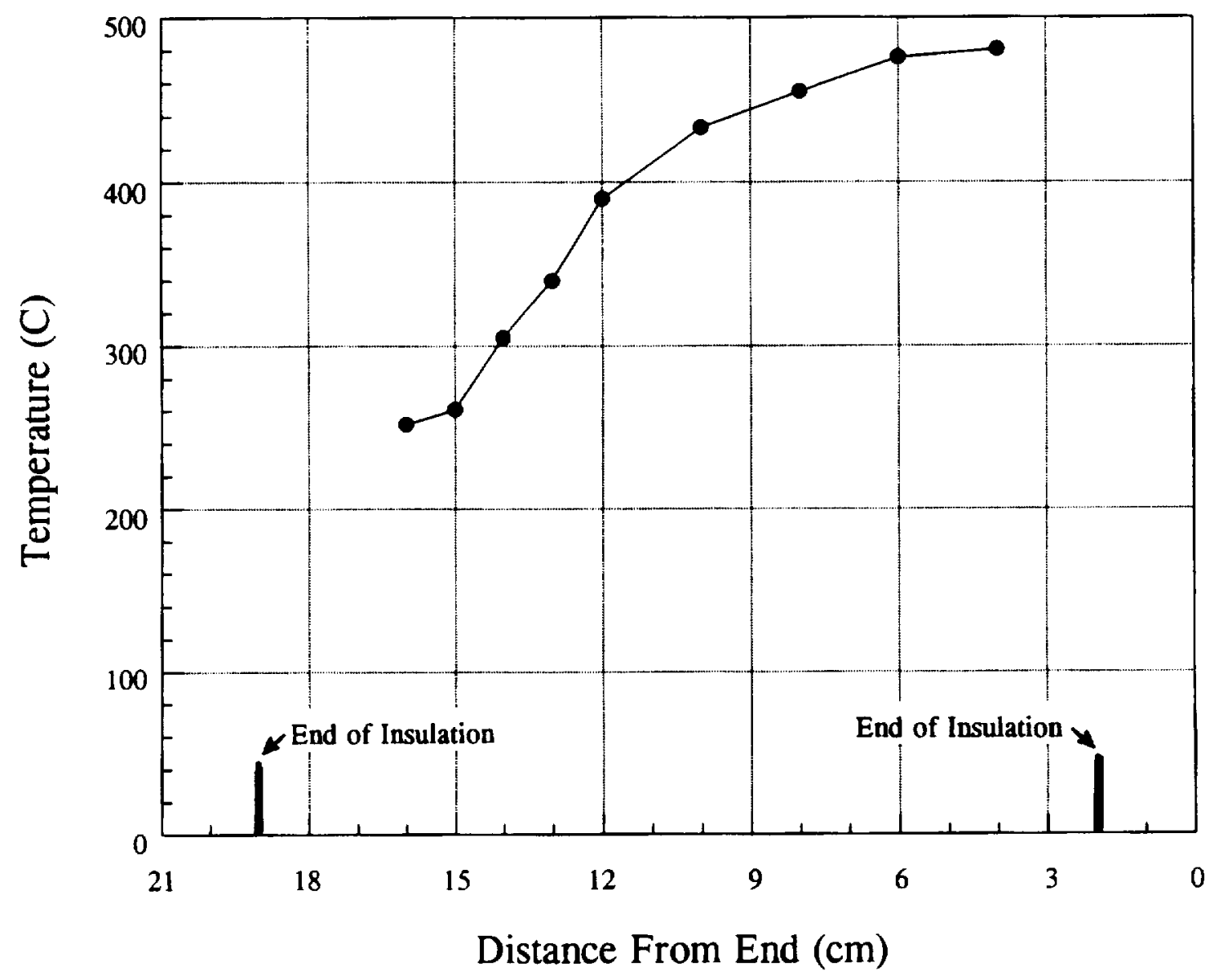

Figure 14. Axial temperature profile of the inside of the outer quartz tube supporting the mirror plates in response to the air cooling in the gap between this tube and the next smaller tube. 
Table 3. Transparent furnace power requirements in various configurations.

\begin{tabular}{|c|c|c|c|}
\hline & Core Temperature $(\mathrm{C})$ & Power (W) & Furnace Modification \\
\hline \multirow[t]{8}{*}{ mirror } & 1200 & 3000 & $\begin{array}{l}\text { Final Configuration, } 4 \text { buffer tubes, octagonal } \\
\text { tube, end fan, } 2 \text { side fans. }\end{array}$ \\
\hline & 1100 & 2100 & Same \\
\hline & 1000 & 1200 & Same, without 2 side fans. \\
\hline & 1000 & 1750 & Hex mirror tube, one buffer tube, 1 side fan \\
\hline & 1000 & 1120 & Standard Transparent Furnace \\
\hline & 800 & 400 & Final Configuration, no cooling \\
\hline & 800 & 560 & Same, add end fan \\
\hline & 800 & 660 & Standard Transparent Furnace \\
\hline
\end{tabular}



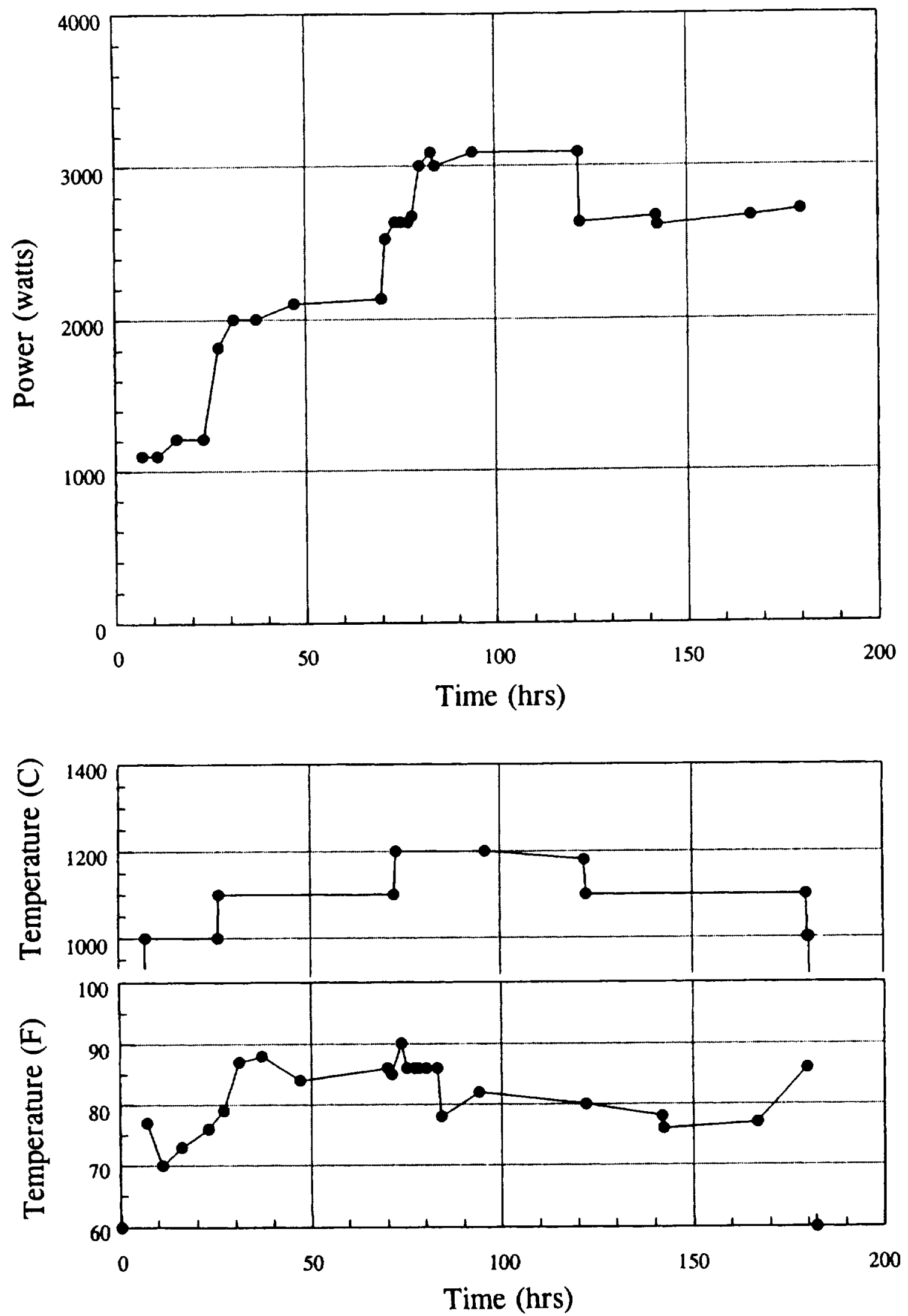

Figure 15. Transparent furnace operating history during feasibility experiments; power, core temperature, and anbient temperature versus time. 
The large power and large power increase at high operating temperature are the result of the $T^{4}$ dependence of radiant power, and the addition of cooling. Table 3 shows the power response of the furnace to configuration change. Only one configuration could be used to reach 1100 and $1200^{\circ} \mathrm{C}$, requiring cooling between the outer furnace tubes and direct cooling of the mirror plates. Even with the end fan, the additional tubes are seen to reduce the power requires of the smaller hex configuration by $30 \%$, back to the level of the standard furnace that is uncooled. Presumably the fan cooling of the hex configuration was responsible for the power increase relative to the standard configuration. At $800^{\circ} \mathrm{C}$ the addition of the end fan is seen to increase the power requirement by $40 \%$, which implies that the cooling is responsible for much of the power increase at high temperature, which is encouraging for development of the furnace. Operation at $800^{\circ} \mathrm{C}$ also shows a $40 \%$ power reduction in furnace power as a result of the addition of buffer tubes when compared with standard furnace operation.

Photographs of furnace operation at $1200^{\circ} \mathrm{C}$ are given in Figs. 16 and 17 . The results presented in this analysis have been compiled in a short period at the end of the program, and, while correct to the best analysis at this writing, are subject to future correction.

Furnace Improvements. The project work has led to a much more complete understanding of transparent furnace technology. During the program further possible improvements in the construction of the furnace have become apparent, both for increasing operating temperature and for decreasing power. $1200^{\circ} \mathrm{C}$ are:

Changes in technology available to the project that are believed to have permitted stable operation at

Certain:

1) Standard mirror coating on plates used in the feasibility experiment.

2) Winter operation ( $>20^{\circ} \mathrm{F}$ cooler furnace environment temperature)

Highly Probable:

1) More uniform cooling air flow over mirrors that were used.

2) More flow between the outer quartz cylinders.

Advances in this program have already been incorporated in commercial furnaces sold by $\mathrm{C} / \mathrm{VI}$ to allow a furnace temperature limit of $1050^{\circ} \mathrm{C}$. Previous research by Insight Scientific had achieved a core temperature of $1150^{\circ} \mathrm{C}$ for 5 minutes before component failure. 


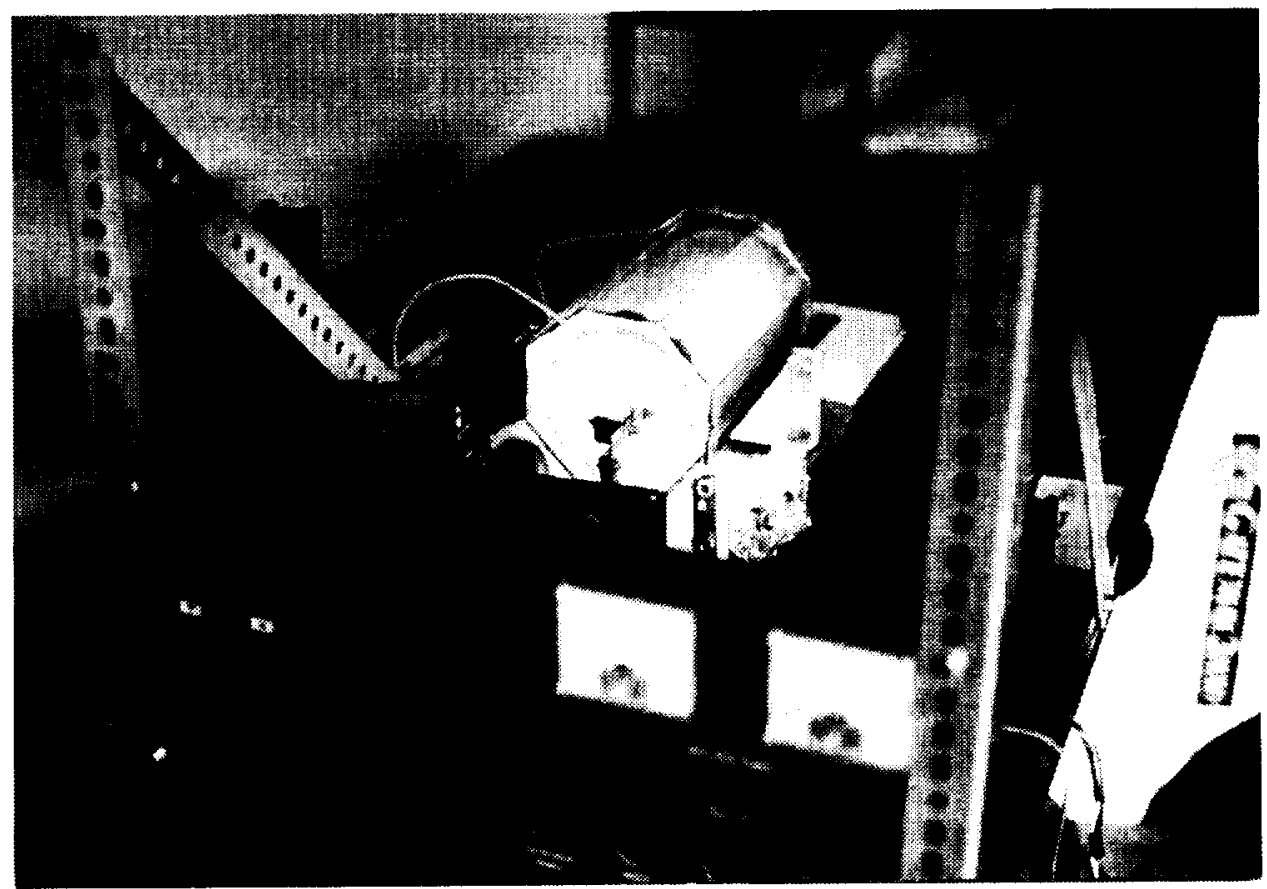

Figure 16. Photograph of transparent furnace operating at $1200^{\circ} \mathrm{C}$.

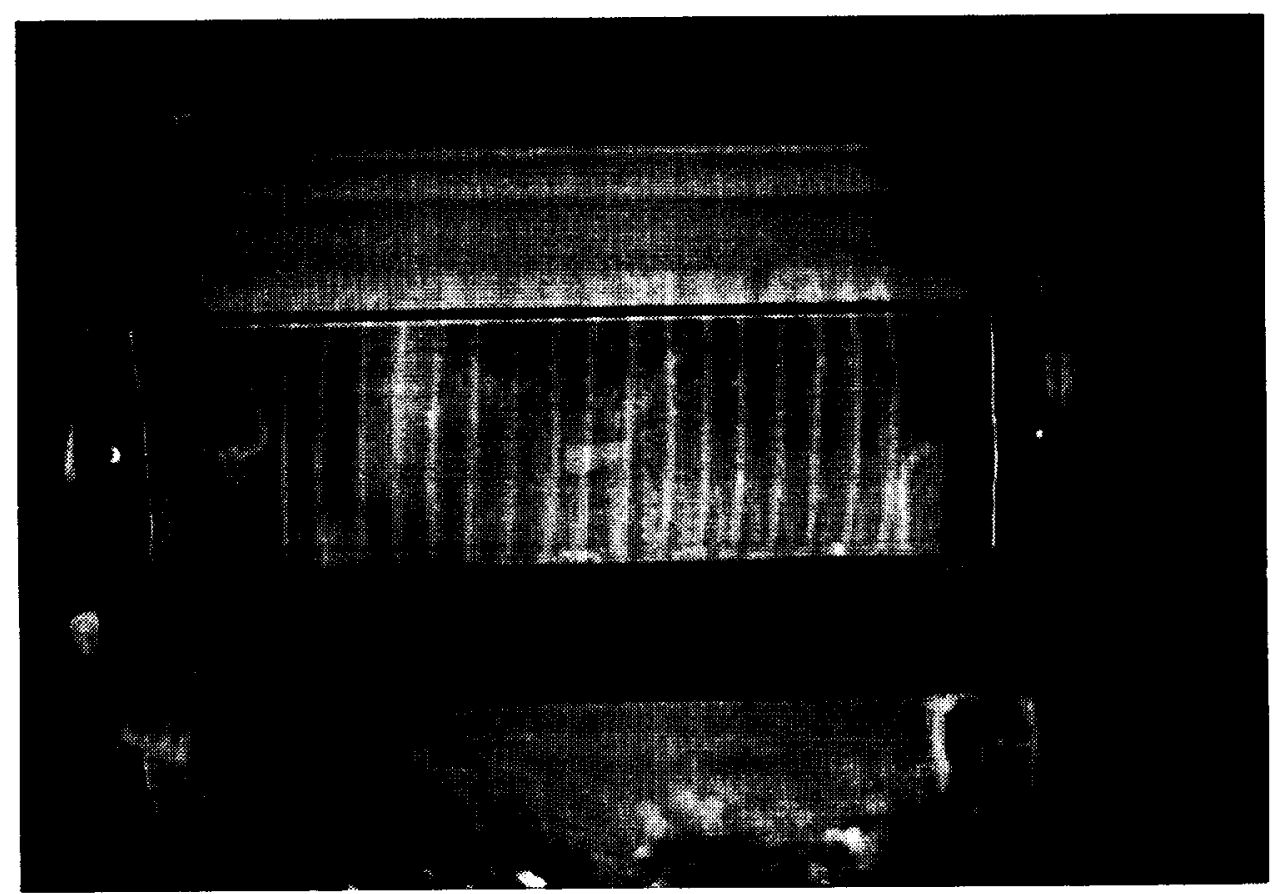

Figure 17. Photograph of transparent furnace operating at $1200^{\circ} \mathrm{C}$ showing coating degradation. (The large blotch and scratches are on the old mirror tube inside the furnace.) 


\section{DISCUSSION OF RESULTS}

The work has shown that there is no fundamental limitation on high temperature transparent furnace operation. Transparent furnace operation at $1200^{\circ} \mathrm{C}$ was demonstrated for 100 hours using active air cooling, although this requires a significant increase in furnace power compared with passive cooling. The furnace was operated at high temperature continuously for over a week. These demonstration experiments showed that internal components of the furnace could operate at $1200^{\circ} \mathrm{C}$ without major degradation. Furnace peak power was over $3 \mathrm{kw}$, but power comparisons show that the new furnace configuration would require less power than the standard furnace if air cooling were not required.

The primary technique that has been used to evaluate the performance of the furnace was to examine the energy balance of the furnace, accounting for the electric power used in terms of radiation, convection, and conduction energy losses. Heat transfer modeling of the transparent furnace was performed in detail, and furnace power was measured at high temperature and in response to cooling and changes in the configuration of the thermal insulation. The modeling was verified by experiments and then used to prediction the benefits of design changes intended to increase the operating temperature of the furnace and to reduce the power used. Since most of the heat energy is lost through the quartz shells rather than out the ends of the furnace, radial temperature profiles were measured for all furnace configurations. Proprietary techniques were developed to reduce furnace power consumption in a follow-up project intended to build an advance transparent furnace for NASA.

Modeling and experiments led to a recognition that radiant beat transfer between quartz shells plays a dominant role in the overall thermal behavior of the transparent furnace. The behavior of quartz in a transparent furnace application was studied as well as alternate, more transparent materials with the intention of possibly reducing infrared heat absorption. The benefits of an increase in transparency do not seem to be justified by the increased cost, the decrease in temperature limits compared with quartz, and the possibility of using an internal reflective coating to reduce the absorption in quartz. Extensive research into infrared mirror coating science and engineering was performed. Methods were developed for increasing mirror operating temperature that involved processing the substrate differently and relocating the coating so that little radiation would be absorbed in the binder or, in the far infrared, the substrate. The primary mechanism of coating degradation seemed to be spalling as a result of differential thermal expansion between the coating and the substrate. Air cooling techniques between quartz insulating shells were demonstrated to prevent mirror coating degradation by preventing overheating of the coating. Degraded mirrors were used to demonstrate the usefulness of absorptive radiant heat containment in the transparent furnace.

The project research has laid the foundation for follow-on work not only by demonstrating transparent furnace operation at $1200^{\circ} \mathrm{C}$, but by identifying the important areas that must be investigated. These are:

The use of improved insulating techniques between the furnace core and the IR mirror tube.

The development of IR mirror coatings that survive temperatures significantly in excess of $500^{\circ} \mathrm{C}$.

- Minimization of convective, conductive, and radiant end losses.

- Heat transfer modeling as a design tool.

- Temperature profile design.

Work in these areas will lead to significant advances in transparent furnace technology and make the prototype furnace a new generation of instrument for materials processing. 


\section{CONCLUSIONS AND SUMMARY OF RESULTS}

The project has resulted in significant advances in many areas of transparent furnace technology. The weaknesses of present transparent furnace technology have been identified in detail and a variety of improvements have been extensively investigated and attempted experimentally. Furnace configuration changes that significantly reduce heat transfer have been demonstrated experimentally, and further large improvements have been identified for inclusion in a future prototype furnace. Furnace heat transfer is driven primarily by radiation between the concentric quartz shells, such that significant furnace design improvements can be achieved by modifying the internal radial temperature profile, adding internal absorbers, and perhaps be using materials that are transparent over a broader wavelength range. Cooling techniques were developed that permitted $1200^{\circ} \mathrm{C}$ operation with present mirror tube technology. The advances and achievements of the project program indicate that the prototype furnace to be constructed will be a new generation of device that performs much better than present transparent furnace technology.

The important objective of the project research was achieved: to demonstrate the feasibility of transparent furnace operation at $1200^{\circ} \mathrm{C}$. Project work has offered solutions to most of the problems with current transparent furnaces, and has demonstrated them in some cases. Techniques for improved radiation containment, reduced convection heat losses, and reduced end losses have been developed. Temperature limits on current infrared mirror tubes were identified as the primary limitation on high temperature operation. Current mirror tube designs were demonstrated to be adequate for high temperature operation if adequate air cooling was provided inside the mirror tube, although at a price of significantly increased power use. Operation at $1200^{\circ} \mathrm{C}$ within the constraints of the project is a significant technological advance and a proof of the possibilities the can be realized for major improvements in future work.

The primary technical benefits of a high temperature transparent furnace are first that it permits optical access to materials processing that requires temperatures that have not been previously accessible. Secondly it provides the capability for development of the many tools and calibration measurements that will be required for non-intrusive high temperature intelligent materials processing. The development of a high temperature transparent furnace would result in major savings for many NASA programs by allowing real time feedback control of materials processing. Such control has been demonstrated to dramatically reduce cycle times and labor investments. Allowing rapid manual interaction with materials processing is of crucial importance for research in space. The transparent furnace developed in this program may lead to the most important economic benefit for NASA - the development of commercial applications for materials processing in space. The benefits of commercial development of the transparent furnaces are extensive and assured by requests by industry for this furnace, which will allow rapid development of high temperature materials processing.

\section{Applications}

There are many generic uses for transparent furnaces in materials processing and fluid and solid mechanics at elevated temperatures. Transparent furnaces can be used for research in crystal growth, sintering, metal joining, and annealing, high temperature materials properties, and the behavior of flowing systems that use high temperature liquids. In the area of crystal growth, some of the capabilities introduced by a transparent furnace are 1) Nucleation can be observed; if multiple nucleation sites occur solidification can be restarted, 2) The melt/solid interface can be viewed as a result of differences in density and emissivity between the liquid and solid, 3) Surface tension effects can be studied as a result of these liquid-solid differences. (This capability is important for microgravity research), 4) Convection can be studied through index of refraction changes with temperature, 5) Internal temperatures can be monitored by tomographic means, and 6) A variety of crystal defects are visible, depending on the optical properties of the crystal.

In other areas, transparent furnaces can be used to investigate high temperature surface tension effects in microgravity as used in thermal storage devices. Long distance microscopy will allow the study of material microstructure, which is crucially important for many processes such as sintering. Finally, the development and use of a wide variety of optical diagnostics will lead to the development of intelligent materials processing in many specific cases. 
Full optical access to furnace applications will allow diagnosis of the subtleties of high temperature processes under microgravity conditions, as well as for future applications in process control in space and on earth. There are many specific applications for both NASA and commercial interests that will now be possible in important processes that only occur at high temperatures. Transparent furnace technology will be a key space station capability, allowing astronauts to interactively perform materials processing experiments in microgravity. The development of a high temperature transparent furnace will create many new opportunities for high temperature material processing research and process control applications. The follow-on program is expected to give NASA important new broad capabilities for advances in high temperature materials processing science. Commercial potential is similarly great because an important class of materials processing techniques occurs in the newly acquired temperature range and can now be studied. For example, important types of crystals that melt in the range of $1000-1200^{\circ} \mathrm{C}$ can be observed, and joining processes that involve melting copper (melting point $1084^{\circ} \mathrm{C}$ ) can be inspected.

\section{ACKNOWLEDGEMENTS}

The author gratefully acknowledges the support of this work by the National Aeronautics and Space Administration under Contract No. NAS3-26665. The assistance of the Technical Monitor Dr. Richard De Witt is also greatly appreciated for his discussions and aid in interactions with Nasa Lewis personnel. Special thanks goes to Dave Yoel, whose help and support has allowed this project to be started, funded, and successfully completed.

\section{REFERENCES}

1. T.B. Reed, "Transparent Furnace for Vapor Crystal Growth," Solid State Research Report, Lincoln Lab, MIT, 1, 21, (1969).

2. D.W. Yoel, and D.M. Garman, "Transparent furnace technology for space applications," International Astronautical Federation Congress, Paper No. IAF-87-047, October, (1987).

3. D.W. Yoel, and T.L. Thomas, "Telescience vapor crystal growth using small satellites, " Proceedings of the 1st Annual USU Conference on Small Satellites, Utah State University, Logan, Utah, October (1987).

4. D.W. Yoel, and S.L. Sperry, Space-based processing of semiconductor materials by chemical vapor transport, American Astronautical Society Science \& Technology Series, 67, AAS 86-559, H. Jacobs, Editor, (1987).

5. P.G. Schunemann, and T.M. Pollak, " $\mathrm{ZnGeP}{ }_{2}$ Crystal Growth Studies using the Horizontal Gradient Freeze Technique," Presented at the Tenth Intnl. Conf. on Crystal Growth, Aug. 16-21, San Diego, CA, (1992),

6. P.H. Garrett, J.G. Jones, D.C. Moore, and J.C. Malas, "Emerging Methods for the Intelligent Processing of Materials," J. Matl. Eng. and Perf., 2, 5, 727-732, (1993).

7. N.M. Wereley, T.F. Zahrah, and F.H. Charron, "Intelligent Control of Consolidation and Solidification Processes," J. Matl. Eng. and Perf., 2, 5, 671-682, (1993).

8. C. Geibel, H. Maier, and R. Schmitt, Journal of Crystal Growth, 86, 386, (1988).

9. R. Triboulet, R. Legros, A. Heurtel, B. Sieber, G. Didier, and D. Imhoff, Journal of Crystal Growth, 72, 90, (1985).

10. K.Y. Lay, D. Nichols, S. McDevitt, B.E. Dean, and C.J. Johnson, Journal of Crystal Growth, 86, 118, (1988).

11. K. Mochizuki, and K. Masumoto, "Melt Growth of CdTe Single Crystals with Controlled Deviation from Stoichiometry, " Mat. Lett., 6, 4, 119-122, Feb. (1988).

12. T. Jasinski and A.F. Witt, "On Control of the Crystal-Melt Interface Shape during Growth in a Vertical Bridgman Configuration for Crystal Growth," J. Crystal Growth, 71, 295-304, (1985).

13. S.L. Lehoczky and F.R. Szofran, Materials Processing in the Reduced Gravity Environment of Space, G.E. Rindone Ed., North-Holland, Amsterdam, 409, (1982). 
14. W.M. Rohsenow, and H. Choi, Heat, Mass, and Momentum Transfer, Prentice-Hall, Englewood Cliffs, NJ, (1961).

15. K.E. Haq, K.H. Behrndt, and I. Kobin, "Adhesion Mechanism of Gold-Underlayer Film Combinations to Oxide Substrates, " J. Vac. Sci. Tech., 6, 1, 148 - 152, (1969).

16. American Institute of Physics Handbook, $3^{\text {rd }}$ Ed., D.E. Gray, Ed., McGraw-Hill, New York, (1972).

17. A.E. Enos, "Stresses Developed in Optical Film Coatings," Applied Optics, 5, 1, 51-61, (1966).

18. Handbook of Thin Film Technology, L.I. Maissel, and R. Glang, Eds., McGraw-Hill, New York, (1983).

19. K.J. Hanszen, Z. Phys. 150, 527, (1958).

20. J.A. Davey, and T. Pankey, "Optical Properties of Cold- and Hot-Deposited Gold Films," J. Appl. Phys., 36, 8, 2571-2576, (1965).

21. H.H. Blau, Jr., and J.R. Jasperse, "Spectral Emittance of Refractory Materials," Applied Optics, 3, 2, 281-285, (1964).

22. K.E. Haq, K.H. Behrndt, and I. Kobin, "Adhesion Mechanism of Gold-Underlayer Film Combinations to Oxide Substrates," J. Vac. Sci. \& Techn., 6, 1, 148-152, (1969).

23. L.G. Schulz, "An Experimental Confirmation of the Drude Free Electron Theory of the Optical Properties of Metals for Silver, Gold, and Copper in the Near Infrared, "J. Opt. Soc. of Am., 44, 7, 540-545, (1954).

24. J.M. Bennett, and E.J. Ashley, "Infrared Reflectance and Emittance of Silver and Gold Evaporated in Ultrahigh Vacuum," Applied Optics, 4, 2, 221-224, (1965).

25. M.A. Angadi, and K. Nallamshetty, Heat mirrors using $\mathrm{CeO}_{2} / \mathrm{Cu} / \mathrm{CeO}_{2}$ multilayer films," J. Matl. Sci. Lett., 8, 391-394, (1989).

26. D.E. McCarthy, "The Reflection and Transmission of Infrared Materials: I, Spectra from 2 to 50 Microns," Applied Optics, 2, 6, 591-595, (1963).

27. E.G. Brame, Jr., J.L. Margrave, and V.W. Meloche, "Infra-red Spectra of Inorganic Solids - II Oxides, Nitrides, Carbides, and Borides," J. Inorg. Nucl. Chem, 5, 48-52, (1957).

28. W.L. Bond, "Notes on Solution of Problems in Odd Job Vapor Coating," J. Opt. Soc. of Am., 44, 6, 429-438, (1954).

29. M.M. Yang, Titanium-oxide Films made by if diode sputtering from a compound target," J. Appl. Phys., 62, 3, 1035-1041, (1987).

30. R. Glang, "Materials and Processes for Passive Thin-Film Components," J. Vac. Sci. and Techn., 3, 2, 37-48, (1966).

31. J.P. Chauvineau, P. Croce, G. Devant, and M.F. Verhaeghe, "Recrystallization of Thin Gold Films: Influence on THeir Electrical Properties," 776-779, (1969).

32. J.T. Jacobs, R.C. Birtcher, and R.N. Peacock, "Temperature Variation of the Resistivity of Epitaxial Gold Films," J. Vac. Sci. and Techn., 7, 2, 339-342, (1970).

33. G.B. Smith, G.A. Niklasson. J.S.E.M. Svensson, and C.G. Granqvist, "Noble-metal-based transparent infrared reflectors: Experiments and theoretical analyses for very thin gold films, " J. Appl. Phys., 59, 2, 571-581, (1986).

34. K.L. Tai, P.A. Turner, and D.D. Bacon, "The Structure of Evaporated- and dc-Sputtered Films of Gold and Silver Deposited on Glass," J. Vac. Sci. Techn., 6, 4, 687-689, (1969).

35. K.H. Betts, R.R. Parsons, and M.J. Brett, "Heat mirrors for greenhouses," 24, 16, Applied Optics, 2651-2654, (1985).

36. J.A. Sheward, "The coating of internal surfaces by PVD techniques," Surf. and Coat. Techn. 54/55, 297-302, (1992). 


\begin{tabular}{|c|c|c|c|c|}
\hline \multicolumn{3}{|c|}{ REPORT DOCUMENTATION PAGE } & & $\begin{array}{l}\text { Form Approved } \\
\text { OMB No. 0704-0188 }\end{array}$ \\
\hline \multicolumn{5}{|c|}{ 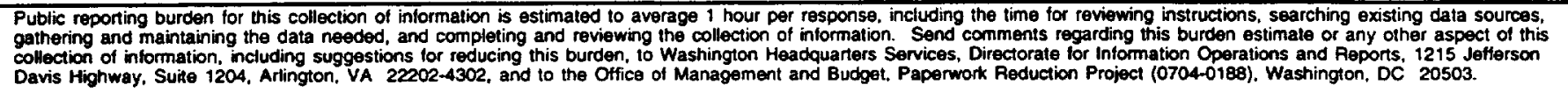 } \\
\hline 1. AGENCY USE ONLY (Leave blank) & $\begin{array}{r}\text { 2. AEPORT DATE } \\
\text { April } 1997\end{array}$ & \multicolumn{3}{|c|}{$\begin{array}{l}\text { 3. AEPORT TYPE AND DATES COVERED } \\
\text { Final Contractor Report }\end{array}$} \\
\hline \multicolumn{3}{|c|}{$\begin{array}{l}\text { 4. TITLE AND SUBTITLE } \\
\text { High Temperature Transparent Furnace Development }\end{array}$} & \multicolumn{2}{|c|}{ 5. FUNDING NUMBERS } \\
\hline \multicolumn{3}{|l|}{$\begin{array}{l}\text { 6. AUTHOR(S) } \\
\text { Stephen C. Bates }\end{array}$} & \multicolumn{2}{|c|}{$\begin{array}{l}\text { WU-963-30-0J-00 } \\
\text { C-NAS3-26566 }\end{array}$} \\
\hline $\begin{array}{l}\text { 7. PERFORMING ORGANIZATION } \\
\text { Thoughtventions Unlimite } \\
\text { P.O. Box } 1310 \\
\text { Glastonbury, Connecticut }\end{array}$ & $\begin{array}{l}\text { NAME(S) AND ADDRESS(ES) } \\
06033\end{array}$ & & \multicolumn{2}{|c|}{ E-10689 } \\
\hline $\begin{array}{l}\text { 9. SPONSORINGMONITORING AG } \\
\text { National Aeronautics and } \\
\text { Lewis Research Center } \\
\text { Cleveland, Ohio } 44135 \text { - }\end{array}$ & $\begin{array}{l}\text { ENCY NAME(S) AND ADDRESS(ES) } \\
\text { Space Administration } \\
3191\end{array}$ & & \multicolumn{2}{|c|}{ NASA CR-202333 } \\
\hline \multicolumn{5}{|c|}{$\begin{array}{l}\text { 11. SUPPLEMENTARY NOTES } \\
\text { Project manager, Richard L. DeWitt, Space Experiments Division, NASA Lewis Research Center, organization code } \\
6728,(216) 433-2601 \text {. For additional information contact Dr. Walter B. Duval, NASA Lewis Research Center, organiza- } \\
\text { tion code } 5110,(216)-433-5023 \text {. }\end{array}$} \\
\hline \multicolumn{4}{|c|}{$\begin{array}{l}\text { 12a. DiSTRIBUTIONAVAILABILITY STATEMENT } \\
\text { Unclassified - Unlimited } \\
\text { Subject Categories } 29,34 \text {, and } 74 \\
\text { This publication is available from the NASA Center for AeroSpace Information, (301) 621-0390. }\end{array}$} & TRIBUTION CODE \\
\hline \multicolumn{5}{|c|}{$\begin{array}{l}\text { This report describes the use of novel techniques for heat containment that could be used to build a high temperature } \\
\text { transparent furnace. The primary objective of the work was to experimentally demonstrate transparent furnace operation at } \\
1200^{\circ} \mathrm{C} \text {. Secondary objectives were to understand furnace operation and furnace component specification to enable the } \\
\text { design and construction of a low power prototype furnace for delivery to NASA in a follow-up project. The basic approach } \\
\text { of the research was to couple high temperature component design with simple concept demonstration experiments that } \\
\text { modify a commercially available transparent furnace rated at lower temperature. A detailed energy balance of the operat- } \\
\text { ing transparent furnace was performed, calculating heat losses through the furnace components as a result of conduction, } \\
\text { radiation, and convection. The transparent furnace shells and furnace components were redesigned to permit furnace } \\
\text { operation at at least } 1200^{\circ} \mathrm{C} \text {. Techniques were developed that are expected to lead to significantly improved heat contain- } \\
\text { ment compared with current transparent furnaces. The design of a thermal profile in a multizone high temperature } \\
\text { transparent furnace design was also addressed. Experiments were performed to verify the energy balance analysis, to } \\
\text { demonstrate some of the major furnace improvement techniques developed, and to demonstrate the overall feasibility of a } \\
\text { high temperature transparent furnace. The important objective of the research was achieved: to demonstrate the feasibility } \\
\text { of operating a transparent furnace at } 1200^{\circ} \mathrm{C} \text {. }\end{array}$} \\
\hline \multirow{2}{*}{\multicolumn{3}{|c|}{$\begin{array}{l}\text { 14. SUBJECT TERMS } \\
\text { High temperature; Transparent; Furnace; Heat shield; Radiation }\end{array}$}} & & 15. NUMBER OF PAGES \\
\hline & & & & $\frac{37}{16 . \text { PAICE CODE }}$ \\
\hline $\begin{array}{l}\text { 17. SECURITY CLASSIFICATION } \\
\text { OF REPORT } \\
\text { Unclassified }\end{array}$ & $\begin{array}{l}\text { 18. SECURITY CLASSIFICATION } \\
\text { OF THIS PAGE } \\
\text { Unclassified }\end{array}$ & $\begin{array}{l}\text { 19. SEC } \\
\text { OF }\end{array}$ & ATION & 20. LIMITATION OF ABSTRACT \\
\hline
\end{tabular}

NSN 7540-01-280-5500 